Article

\title{
Treatment of Tide Gauge Time Series and Marine GNSS Measurements for Vertical Land Motion with Relevance to the Implementation of the Baltic Sea Chart Datum 2000
}

\author{
Sander Varbla ${ }^{1, *(D)}$, Jonas Ågren ${ }^{2,3}$, Artu Ellmann ${ }^{1}$ and Markku Poutanen ${ }^{4}$ (D) \\ 1 Department of Civil Engineering and Architecture, Tallinn University of Technology, Ehitajate Road 5, \\ 19086 Tallinn, Estonia; artu.ellmann@taltech.ee \\ 2 Department of Computer and Geospatial Sciences, University of Gävle, Kungsbäcksvägen 47, \\ 80176 Gävle, Sweden; jonas.agren@hig.se \\ 3 Department of Geodetic Infrastructure, Lantmäteriet, Lantmäterigatan 2C, 80182 Gävle, Sweden \\ 4 Finnish Geospatial Research Institute FGI, National Land Survey, Geodeetinrinne 2, 02430 Masala, Finland; \\ markku.poutanen@nls.fi \\ * Correspondence: sander.varbla@taltech.ee
}

Citation: Varbla, S.; Ågren, J.;

Ellmann, A.; Poutanen, M. Treatment of Tide Gauge Time Series and Marine GNSS Measurements for Vertical Land Motion with Relevance to the Implementation of the Baltic Sea Chart Datum 2000. Remote Sens. 2022, 14, 920. https://doi.org/ $10.3390 /$ rs14040920

Academic Editors: Roland Pail, Pavel Novák, George Vergos and Sergei Badulin

Received: 23 December 2021 Accepted: 12 February 2022 Published: 14 February 2022

Publisher's Note: MDPI stays neutral with regard to jurisdictional claims in published maps and institutional affiliations.

Copyright: (c) 2022 by the authors. Licensee MDPI, Basel, Switzerland. This article is an open access article distributed under the terms and conditions of the Creative Commons Attribution (CC BY) license (https:/ / creativecommons.org/licenses/by/ $4.0 /)$.

\begin{abstract}
Tide gauge (TG) time series and GNSS measurements have become standard datasets for various scientific and practical applications. However, the TG and geodetic networks in the Baltic Sea region are deforming due to vertical land motion (VLM), the primary cause of which is the glacial isostatic adjustment. Consequently, a correction for VLM, either obtained from a suitable VLM model or by utilizing space-geodetic techniques, must be applied to ensure compatibility of various data sources. It is common to consider the VLM rate relative to an arbitrary reference epoch, but this also yields that the resulting datasets may not be directly comparable. The common height reference, Baltic Sea Chart Datum 2000 (BSCD2000), has been initiated to facilitate the effective use of GNSS methods for accurate navigation and offshore surveying. The BSCD2000 agrees with the current national height realizations of the Baltic Sea countries. As TGs managed by national authorities are rigorously connected to the national height systems, the TG data can also be used in a common system. Hence, this contribution aims to review the treatment of TG time series for VLM and outline potential error sources for utilizing TG data relative to a common reference. Similar consideration is given for marine GNSS measurements that likewise require VLM correction for some marine applications (such as validating marine geoid models). The described principles are illustrated by analyzing and discussing numerical examples. These include investigations of TG time series and validation of shipborne GNSS determined sea surface heights. The latter employs a high-resolution geoid model and hydrodynamic model-based dynamic topography, which is linked to the height reference using VLM corrected TG data. Validation of the presented VLM corrected marine GNSS measurements yields a $1.7 \mathrm{~cm}$ standard deviation and $-2.7 \mathrm{~cm}$ mean residual. The estimates are $1.9 \mathrm{~cm}$ and $-10.2 \mathrm{~cm}$, respectively, by neglecting VLM correction. The inclusion of VLM correction thus demonstrates significant improvement toward data consistency. Although the focus is on the Baltic Sea region, the principles described here are also applicable elsewhere.
\end{abstract}

Keywords: Baltic Sea; BSCD2000; geoid; glacial isostatic adjustment; GNSS; tide gauge; sea level; vertical land motion

\section{Introduction}

Tide gauge (TG) time series has become a standard dataset for various scientific and practical applications, whereby the sea level records refer to local solid Earth. The TG records may thus contain both sea level (such as global sea level trend) and solid Earth (such as vertical land motion-VLM) processes. Depending on the application, an independent data source could be required to disentangle these processes in the TG time series. As one of 
the primary (scientific) applications of TG data is to study sea level and its variations [1-4], a common approach is to estimate the VLM rate at a TG station, which is then removed from a TG time series before further data utilization. It is essential to acknowledge here that VLM can be separated into non-linear and linear motions.

Causes for non-linear VLM include, for example, earthquakes generated by plate tectonics [5,6], groundwater pumping [7], and natural resources extraction [8]. These nonlinear motions typically have relatively short spatial scales, making them difficult to model and consider. It would be impossible to obtain sufficient data without complementary space-geodetic techniques. For instance, non-linear VLM can be estimated from global navigation satellite system (GNSS) station time series [9-11] and interferometric synthetic aperture radar (InSAR) analysis [7,12,13]. Due to the non-linearity of the VLM, however, observed motions cannot be extrapolated to the past or future. In addition, while GNSS stations generally provide reliable and high-accuracy data, it may be difficult to separate the signal of non-linear VLM from data noise (e.g., caused by antenna-related errors or site-dependent effects, such as snow on the antenna radome). There is also currently a partial lack of direct co-location between GNSS and TG stations, which may prevent the utilization of GNSS velocities $[9,14]$. The impact of non-linear VLM on TG time series may therefore remain unnoticed and is usually neglected.

Glacial isostatic adjustment (GIA) induced VLM is commonly expressed as a spatially dependent linear trend (i.e., constant in time considering the proportionately short time extent of TG time series) due to the long-lasting viscoelastic response of the Earth [15,16]. It is also the primary cause of linear VLM. In addition to the aforementioned space-geodetic techniques, linear VLM can also be estimated by combining TG data with satellite altimetry records $[9,17,18]$. However, it is necessary to consider that the reliability of altimetrybased results may degrade on approaching coastal areas because of waveform distortions and approximations in atmospheric, sea state, and geophysical corrections $[19,20]$. Alternatively, VLM rates may be obtained from GIA models [21,22] that generally provide longer-wavelength information instead of localized VLM. Due to the flexural rigidity of the lithosphere, the GIA process results mainly in a smooth deformation. The temporal longwavelength linear changes of the geoid [23] can also be derived from GIA modeling [16,22]. For applications that require TG-based sea dynamic topography (DT) determined relative to the geoid $[3,24,25]$, the geoid change may need to be removed from the geocentric VLM estimates (e.g., determined by a space-geodetic technique).

The Fennoscandian Shield (including the whole Baltic Sea region) in Northern Europe is an area of a relatively low temporal VLM variability [11]. The primary cause for VLM is GIA $[16,26,27]$, whereas the contribution from seasonal and nonseasonal velocity variability to VLM is typically modest [11]. Furthermore, the estimated current GIA deceleration of $0.002 \mathrm{~mm} / \mathrm{y}^{2}$ can be considered negligible [28]. Several recent studies conducted in the Baltic Sea region [29-32] have relatedly approximated VLM to be linear and employed only the NKG2016LU model [22]. Similarly, non-linear VLM is neglected in this study, although local non-linear VLM, such as subsidence, has been revealed at some TG stations [33]. NKG2016LU is a semi-empirical VLM model that combines geophysical GIA modeling with geodetic observations, implying that the model may also describe other geophysical processes. Tide gauge data have not been included in the model development, thus allowing the use of the model as an independent source of VLM correction for the TG time series.

Although GNSS time series are often used to estimate VLM, for some applications, the GNSS data itself may require consideration for VLM, too. It is a standard approach that the coordinates of continuously operating reference stations (CORS) are fixed to a defining epoch $\left(t_{0}\right)$ of a national or global reference frame, which is usually in the middle of a GNSS campaign used for a frame establishment or some round time-epoch (e.g., 2000.0). The actual positions of the CORS at a different observation time $(t)$ may differ from the positions at the defining epoch (e.g., in elevation due to VLM). As a result, VLM-generated coordinate differences will be introduced to a GNSS measurement at epoch $t$ because a determined height difference $d h(t)$ (between measurement station and GNSS-CORS) is 
referred to a reference epoch $t_{0}$. Such an approach facilitates consistency between height reference and results of GNSS measurements. However, this only works for measurements conducted on land. For GNSS-based measurements at sea [24,25], such a standard approach may result in discrepancies because the sea level trends do not follow VLM directly (but they do contain the GIA-induced geoid change). Consequently, an offset is introduced to the marine GNSS measurements relative to a reference (Figure 1). Thus, offshore GNSS measurements may require consideration for VLM occurring at land located GNSS-CORS (and strictly also for the smaller geoid change at sea).

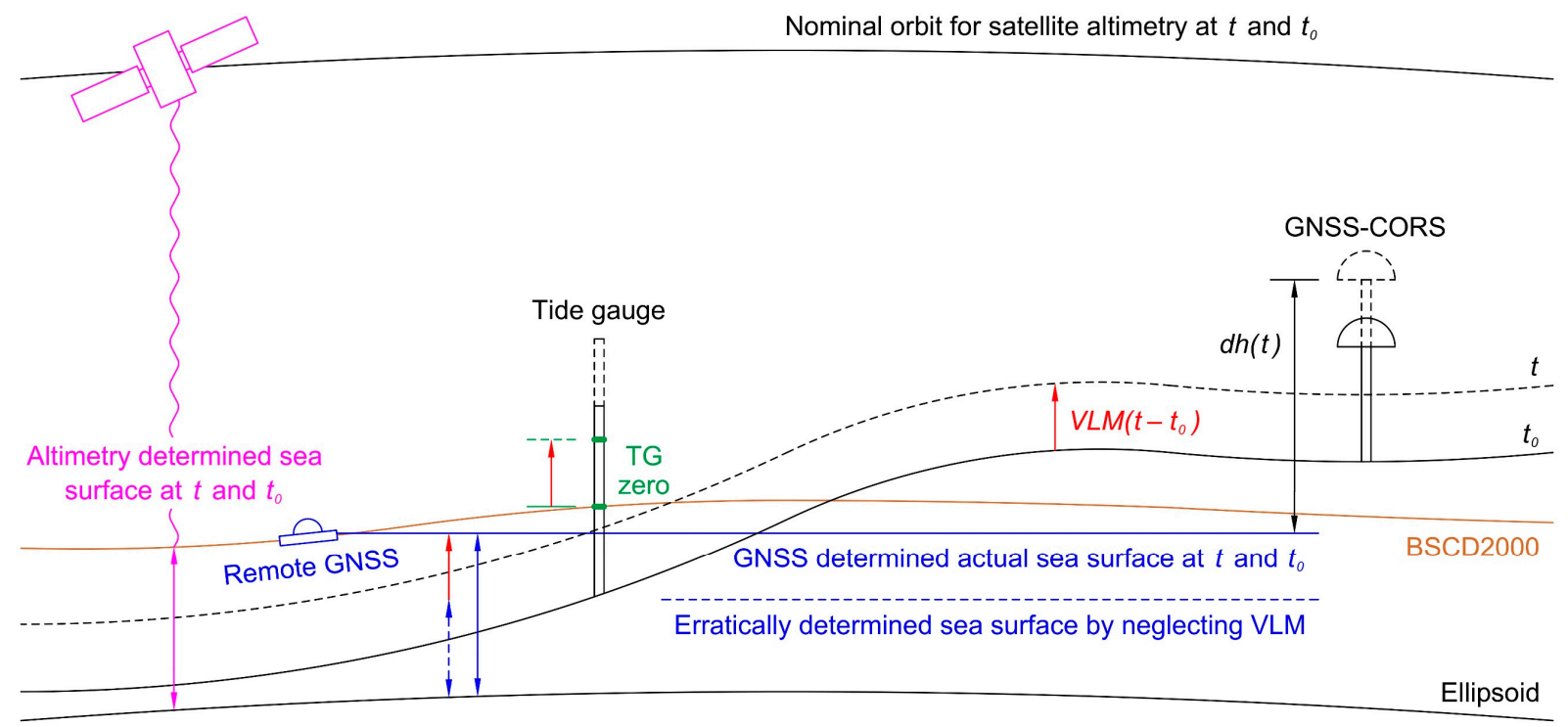

Figure 1. Simplified (assuming that DT and geoid change are negligible) interrelations between VLM ( $V L M$ is the uplift rate, as depicted) affected reference surfaces and stations. The solid lines denote geometry at a reference epoch $t_{0}$, whereas the dashed lines are geometry at a time of observation $t$. Note that BSCD2000 (brown line) coincides with the TG zero and geoid surface (also with sea surface heights in the figure since DT is assumed negligible). Notice that the figure depicts satellite altimetry unaffected by VLM, but in reality, altimetry records do contain GIA-induced geoid change (also refer to Sections 3 and 4).

The common height reference, Baltic Sea Chart Datum 2000 (BSCD2000), has been initiated to facilitate the effective use of GNSS methods for accurate navigation and offshore surveying [34]. Tide gauges of the Baltic Sea region are rigorously connected to the national height systems [33,35] that agree with BSCD2000, which implies that TG readings too, refer to the BSCD2000 (i.e., the zeros of TGs coincide with the BSCD2000 at the reference epoch, neglecting measurement errors in the leveling connections to the height network). Due to the convention, the TG readings at epoch $t$ are initially not transferred for VLM to the epochs of the corresponding height systems (i.e., $t_{0}$ ). Therefore, this contribution aims to review the treatment of the TG time series for VLM. Similarly, the necessity of VLM correction application on marine GNSS measurements is discussed. The underlying principles that allow consistent comparisons between various datasets relative to a common reference and time-epoch (i.e., BSCD2000) are examined, and potential error sources are described. Numerical examples are studied to illustrate the presented principles.

The outline of this paper is as follows. Considering the importance of VLM correction for various TG-related applications, the treatment of TG data in the northern part of the Baltic Sea region is reviewed in Section 2. Specifically, VLM affects the Estonian, Finnish, and Swedish TGs most. The relation between TGs and the BSCD2000 is introduced. The occasional necessity of VLM correction for marine GNSS measurements is explained next, in Section 3. The paper continues with a discussion in Section 4 and ends with a summary in Section 5. 


\section{Treatment of Tide Gauge Time Series for Vertical Land Motion}

Tide gauge stations measure sea level heights relative to the TG zero, which is usually connected to a nearby geodetic benchmark by geodetic precise leveling. These local benchmarks are connected to the national height systems, sometimes as a part of the height reference network, sometimes only with a sloppy connection [35,36]. Besides poor connections, TG records may contain vertical datum shifts also due to, for example, natural disasters, human errors, or insufficient maintenance and documentation [6,37]. Historically, national height systems have been based on one or more TG determined mean sea level estimate(s). The mean sea level is not an equipotential surface due to semi-persistent external forces that affect the mean DT variability (in both temporal and spatial domains). There may thus be discrepancies also between various contemporary national height systems due to different selections of TG stations and epochs for height system realizations [36,38]. For the same reason, there is also a possibility of a national height system distortion $[39,40]$. These reasons make it difficult to use (historic) TG data in a unified height system (i.e., relative to a common equipotential reference surface), especially over larger areas. A common geodetic height system of high quality is required.

The corrections to a fixed vertical datum are often neglected. For instance, when TG time series is used in oceanographic research, the focus is typically on trends and correlations. Assuming that the VLM trend is linear, such a simplification allows determination of the absolute sea level ( $A S L$ ) relative to an arbitrary vertical datum:

$$
\operatorname{ASL}(\varphi, \lambda, t)=\operatorname{RSL}\left(\varphi, \lambda, t, t_{0}\right)+\operatorname{VLM}(\varphi, \lambda) \cdot\left(t-t_{0}\right)
$$

where RSL is the relative sea level measured by a TG and VLM represents the VLM rate (estimated by a suitable method, cf. Introduction) at a TG location with geodetic coordinates $(\varphi, \lambda)$. Note that $t$ represents a TG observation epoch (decimal years) referring to an arbitrary reference epoch $t_{0}$. Depending on the application, VLM in Equation (1) can be expressed relative to different reference surfaces: reference ellipsoid (geocentric or absolute VLM-VLM geocentric), geoid (leveled VLM-VLM leveled), or mean sea level (apparent VLM-VLM apparent). These quantities can be related to each other as:

$$
\operatorname{VLM}_{\text {geocentric }}(\varphi, \lambda)=\operatorname{VLM} M_{\text {leveled }}(\varphi, \lambda)+G C(\varphi, \lambda)=\operatorname{VLM} M_{\text {apparent }}(\varphi, \lambda)+G C(\varphi, \lambda)+S L T(\varphi, \lambda)
$$

where GC represents geoid change (i.e., geoid rise in the Baltic Sea region) and SLT sea level trend. Figure 2 visualizes the rate of $V L M_{\text {leveled }}$ and geoid rise in the Baltic Sea region, according to the NKG2016LU model [22].

\subsection{Baltic Sea Chart Datum 2000}

In the Baltic Sea region, European Vertical Reference System (EVRS) based national height systems have been adopted, where heights are referred to the Normaal Amsterdams Peil (NAP). In Estonia, Finland, and Sweden, the realizations are named as EH2000 [33,35], N2000 [41] and RH 2000 [42,43], respectively (Table 1). Due to the strong influence of GIA, all these realizations have employed the NKG2005LU VLM model [43,44] to reduce leveling observations to the common reference epoch 2000.0 (refer to Figure 3a).

Table 1. National height systems, corresponding $t_{0}$ and the number of active TG stations (in 2021) managed by national TG authorities (cf. Figure 2).

\begin{tabular}{ccccc}
\hline Country & Height System & $\boldsymbol{t}_{0}$ & Number of TG Stations & Managing Authority \\
\hline Estonia & EH2000 & 2000.0 & 15 & Estonian Environment Agency (EEA) \\
\hline Finland & N2000 & 2000.0 & 14 & Finnish Meteorological Institute (FMI) \\
\hline Sweden & RH 2000 & 2000.0 & 54 & Swedish Meteorological and Hydrological Institute (SMHI) \\
\hline
\end{tabular}




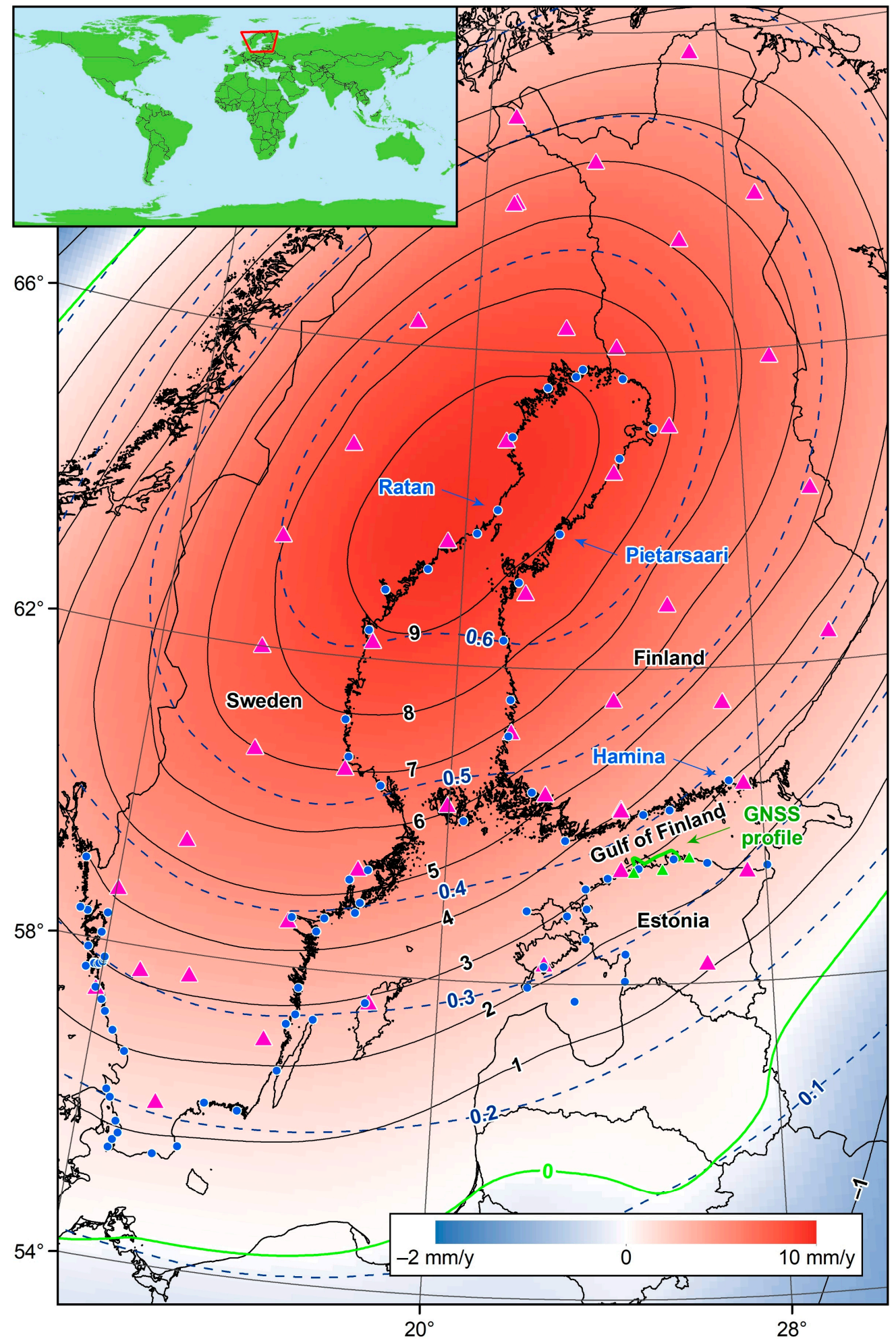

Figure 2. Rate [unit: $\mathrm{mm} /$ year] of $V L M_{\text {leveled }}$ in the Baltic Sea region according to the NKG2016LU model [22]. The accompanying geoid rise (about an order of magnitude smaller than VLM) is shown with dashed blue isolines. Blue circles denote active Estonian, Finnish, and Swedish TG stations (in 2021) managed by national TG authorities. Magenta triangles show the locations of national GNSS-CORS that also belong to the EUREF Permanent GNSS Network (in 2021). The three green triangles denote Estonian GNSS-CORS employed for the marine GNSS profile computations. 
(a)



(b)



Figure 3. Simplified schematics of (a) reductions of leveling observations to a common uplift reference epoch 2000.0 (the three tilted lines symbolize different VLM rates at different locations) and (b) application of VLM correction to the TG time series (for simplicity, the DT is assumed zero at the time-epoch 2000.0). Note that the separation between BSCD2000 and absolute sea level trend in (b) represents rising sea levels. The dashed lines and arrows denote historical data since the beginning of measurements.

Consequently, these national height systems refer approximately to the same reference level. The difference between N2000 and RH 2000 is a few millimeters [41,45], and the EH2000 reference level appears to be approximately $1 \mathrm{~cm}$ higher than those (according to offsets of national height systems relative to EVRF2019 [46]; see also [35]). Such discrepancies can be identified from the common pan-continental adjustment of national leveling networks [47]. However, as all height systems are affected by leveling errors over longer distances, also EVRF2019, it is difficult to say how accurate these system difference estimates are.

Another convincing evidence for accurate knowledge about the national height systems is, for example, the NKG2015 quasigeoid model [48] (over marine areas, the geoid coincides with the quasigeoid, henceforth the shorter term will be used). From a 1-parameter fit (i.e., by removing a vertical offset) to the GNSS-leveling points of the Northern Europe countries, a standard deviation estimate of $2.85 \mathrm{~cm}$ was achieved for the model. It is also important to note that the aforementioned height systems are considered static. No further corrections are introduced post-realizations, even though the networks deform due to VLM. The reference epoch for VLM is here 2000.0.

A similar effort has been initiated to adopt BSCD2000, a common NAP referred height reference system with reference epoch 2000.0, for the Baltic Sea hydrographic surveying and engineering, nautical charts and water level information [34,49]. Offshore, BSCD2000 will be realized through GNSS and high-resolution $(0.01 \times 0.02$ arc-deg) geoid modeling, while onshore, BSCD2000 will be compatible with the national height system realizations of the Baltic Sea countries (e.g., EH2000, N2000, and RH 2000) and will coincide with national geoid models to allow seamless height transitions (this will be achieved through 
the blending of the models, developed by different geoid computation centers [50]). For this purpose, the Baltic Sea is being densely covered by ship- and airborne marine gravity data $[24,51-55]$ to allow high-accuracy marine geoid modeling. Note that since the provided discussion is limited to the Estonian, Finnish, and Swedish height system realizations, an interested reader is encouraged to read additional details concerning BSCD2000 and the other Baltic Sea countries from [34,49,50].

Importantly, the described EVRS-based national height systems (EH2000, N2000, and RH 2000), EVRS itself, and BSCD2000 use the zero-tide permanent tide concept [56]. However, the zero-tide concept is not preferred for oceanographic applications as it introduces a latitude-dependent tilt to the sea level. The (normal) heights relative to BSCD2000 should be thus converted to the mean-tide concept instead. According to the EVRS conventions (cf. Section 5 of [57]), the correction for normal heights is:

$$
H_{\text {mean-tide }}(\varphi)=H_{\text {zero-tide }}(\varphi)-0.09940+0.29541 \sin ^{2} \varphi+0.00042 \sin ^{4} \varphi,
$$

where heights are given in meters, and $\varphi$ is the geodetic latitude of a point of interest (e.g., a TG station). Since BSCD2000 refers to the NAP level, it would be preferred that the conversion is conducted relative to NAP, which is then kept fixed independently of the permanent tide concept. This implies that the following correction should be used instead:

$$
H_{\text {mean-tide }}(\varphi)=H_{\text {zero-tide }}(\varphi)+0.29541\left(\sin ^{2} \varphi-\sin ^{2} \varphi_{N A P}\right)+0.00042\left(\sin ^{4} \varphi-\sin ^{4} \varphi_{N A P}\right) \text {, }
$$

where $\varphi_{N A P}$ is the geodetic latitude of NAP $\left(52^{\circ} 22^{\prime} 53^{\prime \prime}\right.$ [58] in the European Terrestrial Reference System 1989).

\subsection{Tide Gauge Time Series in Relation to the Baltic Sea Chart Datum 2000}

A principal component is that the TG stations are rigorously connected to the corresponding national height systems EH2000, N2000, and RH 2000 via precise leveling [33,35]. In addition, regular re-leveling is conducted to verify the stability of TG stations. The determined discrepancies (e.g., due to localized subsidence) are documented and accounted for in the TG time series. Similarly, the TGs are checked for zero drift. The data are adjusted accordingly if TG zero has drifted from its initial position. Such an approach means that the zero values of TGs should approximately coincide with the same equipotential reference surface (i.e., the geoid) at the reference epoch of a height system (e.g., epoch 2000.0 for the Baltic Sea region). This permits the expression of the contemporary TG readings directly as DT relative to the geoid at the system reference epoch, which is primarily needed for studying specific oceanographic processes. The TG determined sea levels are thus referred to the national geoid models, as well as to the BSCD2000. However, it is essential to note that for rigorous applications, these TG data should be checked for datum consistency (i.e., jumps in the data) by the data user, since the data provided by managing authorities may not always be completely reliable.

Considering the above and assuming the VLM trend to be linear allows Equation (1) to be modified as (note that the general formula of Equation (1) is still valid):

$$
D T_{A S L}(\varphi, \lambda, t)=D T_{R S L}\left(\varphi, \lambda, t, t_{0}\right)+V L M_{\text {leveled }}(\varphi, \lambda) \cdot\left(t-t_{0}\right),
$$

where $D T_{R S L}$ is relative DT compiled by the VLM corrupted TG readings, whereas $D T_{A S L}$ is the estimated absolute DT that reflects the actual sea level heights. Since the geoid at the reference epoch $t_{0}$ is now chosen as a reference surface, VLM correction should also be referred to the geoid (i.e., $V L M_{\text {leveled }}$ is to be used). The geoid change should thus not be included within the VLM correction for DT. Instead of an arbitrary epoch, the system reference epoch $t_{0}$ is now used for calculating the VLM correction. On epoch $t_{0}$, the VLM correction is zero (refer to Figure $3 \mathrm{~b}$ ). Table 1 lists $t_{0}$ for Estonian, Finnish, and Swedish TG time series (i.e., 2000.0), whereby the accordingly reduced observations by 
Equation (5) (i.e., absolute DT) can be used consistently with the other Baltic Sea region geodetic infrastructure.

Note that the relative DT time series can also be transformed to any arbitrary reference epoch $t_{A}$ :

$$
D T_{R S L}\left(\varphi, \lambda, t, t_{A}\right)=D T_{R S L}\left(\varphi, \lambda, t, t_{0}\right)+V L M_{\text {leveled }}(\varphi, \lambda) \cdot\left(t_{A}-t_{0}\right),
$$

whereby the following modified Equation (5):

$$
D T_{A S L}(\varphi, \lambda, t)=D T_{R S L}\left(\varphi, \lambda, t, t_{A}\right)+\operatorname{VLM}_{\text {leveled }}(\varphi, \lambda) \cdot\left(t-t_{A}\right),
$$

results in the same absolute DT as the initial Equation (5). Derived Equation (7) implies no correct choice for a reference epoch as long as the VLM correction is applied consistently. Such a consistent reference epoch allows practical use of the estimated absolute DT. For example, if the objective is to study mean DT around the Baltic Sea, the resulting absolute mean DT estimates refer to the geoid, thus providing a basis to study and quantify the occurring oceanographic processes (note that Equation (4) should also be considered). Conversely, inconsistent use of reference epoch (e.g., terms $D T_{R S L}\left(\varphi, \lambda, t, t_{0}\right)$ and $V L M_{\text {leveled }}(\varphi, \lambda) \cdot\left(t-t_{A}\right)$ are employed together) would produce absolute mean DT estimates that do not refer to the same equipotential reference surface, potentially ensuing in misinterpretation of the results. In case a common reference epoch does not exist, it should be established, but similar use of TG data in a common system also requires that zero values of TGs refer to the same equipotential surface at an established reference epoch (e.g., see [59] for a potential method to connect TG stations to a common system). On the other hand, if the objective is to study sea level trends, adopting a common system may not be beneficial (i.e., consistent use of reference epoch is not mandatory).

\subsection{Numerical Examples}

The hourly open access TG data from SMHI [60] and FMI [61] (cf. Table 1) are used for presenting the TG time series from 1928 to 2021 for Ratan (Sweden) and Pietarsaari and Hamina (Finland), respectively (refer to Figure 2 for the TG locations). Since FMI currently provides open access TG data only from 1971, the Finnish TG time series are complemented with monthly mean sea level data from the Permanent Service for Mean Sea Level (PSMSL) [62,63] for the period 1928-1970 to examine the most extended common period for all three TGs. Note that the Finnish PSMSL sea level data is also initially sourced from FMI. These monthly mean sea levels were first converted to the N2000 height system (i.e., to relative DT) from the initial PSMSL revised local reference $(R L R)$ system:

$$
D T_{R S L}\left(\varphi, \lambda, t, t_{0}\right)=R L R(\varphi, \lambda, t)-C_{P S M S L}+H_{B M},
$$

where $C_{P S M S L}$ is a PSMSL conversion factor associated with the selected TG station (11.025 $\mathrm{m}$ and $7.800 \mathrm{~m}$ for Pietarsaari and Hamina, respectively) and $H_{B M}$ represents a local benchmark height in N2000 (correspondingly $4.487 \mathrm{~m}$ and $1.076 \mathrm{~m}$ ).

For the sake of compatibility, the hourly SMHI, and FMI TG datasets were also averaged to monthly means. The FMI-based and PSMSL-based relative DT for 1971-2019 (the PSMSL datasets end with 2019) were then compared for validation, yielding $-0.3 \mathrm{~mm}$ and $0.2 \mathrm{~mm}$ average discrepancies for Pietarsaari and Hamina TG time series, respectively. Such minor discrepancies indicate a good datum consistency between the two datasets, which are thus suitable for use together. The corresponding estimated standard deviation values of differences are $3.7 \mathrm{~mm}$ and $4.2 \mathrm{~mm}$ due to a few outliers that appear as random and would therefore not affect sea level trend estimations. Generally, the differences are within $\pm 1 \mathrm{~mm}$. Although the datums appear consistent in these examples, it is usually recommended to use metric PSMSL data instead of revised local reference data, since the latter may not always be reliably reduced to a common datum. The metric data is entered into the PSMSL data repository precisely as obtained from the managing authorities. Thus, 
the user should check these data themselves for inconsistencies (i.e., jumps in the data) before further data utilization.

The derived monthly averaged DT estimates (SMHI, FMI, and PSMSL obtained data) were next converted from the zero-tide to the mean-tide concept according to Equation (4). A linear trend was then fitted to the monthly averaged TG time series (FMI and PSMSL data are considered together for Finnish TG stations) in the least-squares sense (similarly to [32]) to approximate relative and absolute sea level trends. Importantly, the residuals of monthly averaged DT estimates (after de-trending) are not representing a pure white noise process due to the presence of time-correlated sea level variability (e.g., due to atmospheric and geophysical signals [64]; the residuals are also not normally distributed). Moreover, the sea level rise appears not to be a constant [28,31] (in this study, it is simplified by a linear trend). A more rigorous approach could hence be needed for a more reliable trend estimation (e.g., see [65]). However, the primary aim here is to demonstrate the application of VLM correction, which is a linear process.

The monthly averaged relative sea level (i.e., $D T_{R S L}$ ) time series for Ratan TG are presented in Figure 4a. As Ratan is near the epicenter of the Fennoscandian post-glacial uplift (cf. Figure 2; $V L M_{\text {leveled }}=9.5 \mathrm{~mm} / \mathrm{y}$ and $\sigma_{V L M}=0.18 \mathrm{~mm} / \mathrm{y}$ according to NKG2016LU), a strong negative trend of $-7.5 \mathrm{~mm} / \mathrm{y}$ dominates. The absolute sea level (i.e., $D T_{A S L}$ ) was estimated by Equation (5), revealing an expected rising sea level trend of $2.0 \mathrm{~mm} / \mathrm{y}$ (Figure $4 \mathrm{~b}$ ). This estimate represents an average annual sea level rise over the examined 94 years. Due to sea level rise acceleration, the current rate estimate is higher (see also [32]). From 1993 to the present, the absolute sea level trend rate was estimated at $4.4 \mathrm{~mm} / \mathrm{y}$ (Figure $4 \mathrm{~b}$ ), which is more than twice as fast. Yet, due to the shorter period (29 years), this estimate may also contain interdecadal sea level variability (e.g., it has been suggested that the length of TG time series should be at least 60 years for reliable evaluations $[1,66])$.

Note that all the sea level estimates are given in the Swedish height system RH 2000, which coincides with the BSCD2000 (both using the mean-tide concept). Additionally, notice that at the epoch 2000.0 (i.e., $\left.t_{0}\right)$ the relative and absolute sea level estimates $(0.264 \mathrm{~m}$ according to the trend in Figure 4 sub-plots a and $b$ ) coincide. This coinciding value can be considered a mean DT estimate at the Ratan TG in mean-tide BSCD2000 (epoch 2000.0) over the period in question (from 1928 to 2021). However, the mean DT may also include shorter-term (e.g., seasonal or annual) variations (depending on the temporal estimation extent) that are excluded from the presented linear sea level trend. For instance, this is indicated by the variation of monthly averaged DT in Figure 4.

An additional test was conducted where deliberate errors were introduced to the results. The mistakes include (i) use of $V L M_{\text {geocentric }}(10.2 \mathrm{~mm} / \mathrm{y}$ at the Ratan TG station; $\left.\sigma_{V L M}=0.18 \mathrm{~mm} / \mathrm{y}\right)$ instead of $V L M_{\text {leveled }}$ to estimate absolute sea levels from the monthly averaged relative sea level time series and (ii) use of an arbitrarily selected epoch 1980.0 instead of epoch 2000.0 as a reference for the VLM correction. The (erroneous) results of this test are shown in Figure 4c. First, it can be noticed that the estimated rising sea level trend of $2.0 \mathrm{~mm} / \mathrm{y}$ (Figure $4 \mathrm{~b}$ ) increases to $2.7 \mathrm{~mm} / \mathrm{y}$ (over the examined 94 years) since a significant geoid change signal is now included (notice in Figure 2 that Ratan is near the epicenter of the geoid rise maximum). Such a trend overestimation resulting from the wrong reference surface for the VLM correction (reference ellipsoid instead of geoid) can lead to a severe misinterpretation of the climate-related sea level trend signal. The geoid change signal prominent in the Baltic Sea region is primarily a result of GIA. Secondly, due to the wrong choice of reference epoch, the mean DT estimate at epoch 2000.0 nearly doubles from $0.264 \mathrm{~m}$ to $0.467 \mathrm{~m}$. Such a significant increase in the estimate can result in a misconception concerning the occurring oceanographic processes.

Similar to the Ratan TG, the Pietarsaari TG relative sea level time series presents a strong negative trend (Figure 5a). On the other hand, notice how the estimated trend for Hamina, which is the Finnish TG furthest from the uplift epicenter (cf. Figure 2; $V L M_{\text {leveled }}=3.0 \mathrm{~mm} / \mathrm{y}$ and $\sigma_{V L M}=0.18 \mathrm{~mm} / \mathrm{y}$ ), is $-0.8 \mathrm{~mm} / \mathrm{y}$ (Figure 6a). This suggests that the sea level and solid Earth processes approximately compensate each other over 
the examined period. The absolute sea levels for Pietarsaari $\left(V L M_{\text {leveled }}=8.9 \mathrm{~mm} / \mathrm{y}\right.$ and $\sigma_{V L M}=0.17 \mathrm{~mm} / \mathrm{y}$ ) and Hamina TGs were estimated similarly to Ratan TG. It can be noticed that the resulting absolute sea level trends of $2.2 \mathrm{~mm} / \mathrm{y}$ for both (Figures $5 \mathrm{~b}$ and $6 \mathrm{~b}$ ) are slightly larger than the Ratan estimate of $2.0 \mathrm{~mm} / \mathrm{y}$. Errors in the used VLM model could cause such differences, but also note that the sea level rise in the Baltic Sea is not uniform [30]. The estimated standard uncertainties of NKG2016LU are 0.17 to $0.18 \mathrm{~mm} / \mathrm{y}$ in these locations [22]. Additionally, deliberate errors were also introduced to the Pietarsaari $\left(V L M_{\text {geocentric }}=9.6 \mathrm{~mm} / \mathrm{y}\right.$ and $\left.\sigma_{V L M}=0.17 \mathrm{~mm} / \mathrm{y}\right)$ and Hamina $\left(V L M_{\text {geocentric }}=3.4 \mathrm{~mm} / \mathrm{y}\right.$ and $\left.\sigma_{V L M}=0.18 \mathrm{~mm} / \mathrm{y}\right) \mathrm{TG}$ data processing, results of which are shown in Figures $5 \mathrm{c}$ and $6 \mathrm{c}$, respectively. A similar trend overestimation can be noticed at these two TG stations, as was the case at the Ratan TG station. The overestimation is slightly smaller at the Hamina TG station due to the reduced impact of geoid change (cf. Figure 2).

The comparison between Figures $4 \mathrm{~b}$ and $6 \mathrm{~b}$ reveals a slight difference (approximately one centimeter) in the estimated absolute sea level (according to the trend) relative to the mean-tide BSCD2000. For instance, at the epoch 2000.0, the estimates are $0.264 \mathrm{~m}$ and $0.272 \mathrm{~m}$ for Ratan and Hamina TGs, respectively. Such a small difference may be due to the estimation uncertainty, but spatial variations in the mean DT can also cause the discrepancy. Although the mean DT difference is slight between the examined TG station locations, the mean DT variations in the Baltic Sea exceed a decimeter (e.g., see the example provided in [49]). This illustrates how there can be discrepancies between used height systems if different TGs are employed for different height systems realizations, as was discussed in Section 2. In the present case, however, all the results refer to the same equipotential reference surface and are compatible (i.e., using the mean-tide concept, the monthly averaged absolute sea level estimates of Ratan, Pietarsaari, and Hamina TGs are directly comparable). The monthly averaged absolute sea level estimates are also highly correlated, with the correlation coefficient being 0.994 between the Ratan and Pietarsaari TGs time series. Although Hamina is in a separate basin of the sea (cf. Figure 2), the resulting correlation coefficients are 0.960 and 0.965 when data from Hamina TG are compared to data from Ratan and Pietarsaari TGs, respectively. Note that, according to [64], the sea level oscillates almost synchronously in the Baltic Sea.

On the other hand, by using an arbitrarily selected epoch 1980.0 as a reference for the VLM correction, the mean DT (according to the trend) estimates are $0.467 \mathrm{~m}$ (Figure $4 \mathrm{c}$ ) and $0.341 \mathrm{~m}$ (Figure 6c) for Ratan and Hamina TGs, respectively (the estimates are similar even with the correct use of $V L M_{\text {leveled }}$ instead of the currently used $\left.V L M_{\text {geocentric }}\right)$. Essentially, the wrong choice of the reference epoch has resulted in a significant mean DT tilt since the obtained estimates do not refer to the same equipotential surface. An attempt to interpret such mean DT estimates can lead to results that do not represent the actual oceanographic processes. This example illustrates well why employing the correct reference epoch has utmost importance (as indicated in Section 2.2).

\section{Theoretical Mean Sea Level for Finnish Tide Gauge Data}

Notice that in Figures 5a and 6a, a so-called theoretical mean sea level is presented [67]. These are annual estimates (approximated by the Finnish Meteorological Institute) for the long-term expected values of relative sea levels at the Finnish TG stations. In estimating the theoretical mean sea level, the VLM, global sea level trend, and changes in the Baltic Sea water balance are considered according to the most recent knowledge. It appears from Figures 5a and 6a that in 1993 (notice a difference in the trends before and after 1993) the estimation of theoretical mean sea level was improved to keep the estimates synchronized with the true sea level. The trends of theoretical mean sea levels of Pietarsaari and Hamina TGs since 1993 (to present) are correspondingly $-4.6 \mathrm{~mm} / \mathrm{y}$ and $1.4 \mathrm{~mm} / \mathrm{y}$ and seem to approximately follow the relative sea level trends estimated (as described in Section 2.3) from actual TG data, which are respectively $-4.7 \mathrm{~mm} / \mathrm{y}$ and $1.5 \mathrm{~mm} / \mathrm{y}$ for the same period (Figures $5 \mathrm{a}$ and $6 \mathrm{a}$ ). The corresponding absolute sea level trends are $4.2 \mathrm{~mm} / \mathrm{y}$ and $4.5 \mathrm{~mm} / \mathrm{y}$ (Figures $5 \mathrm{~b}$ and $6 \mathrm{~b}$ ). 
(a)

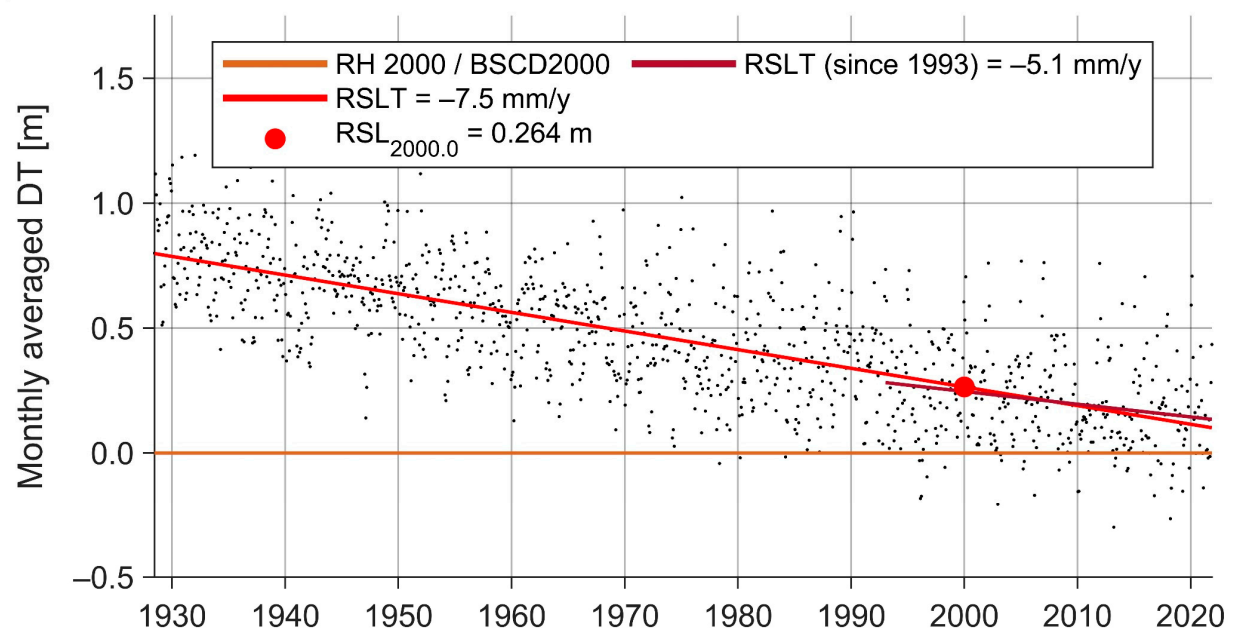

(b)

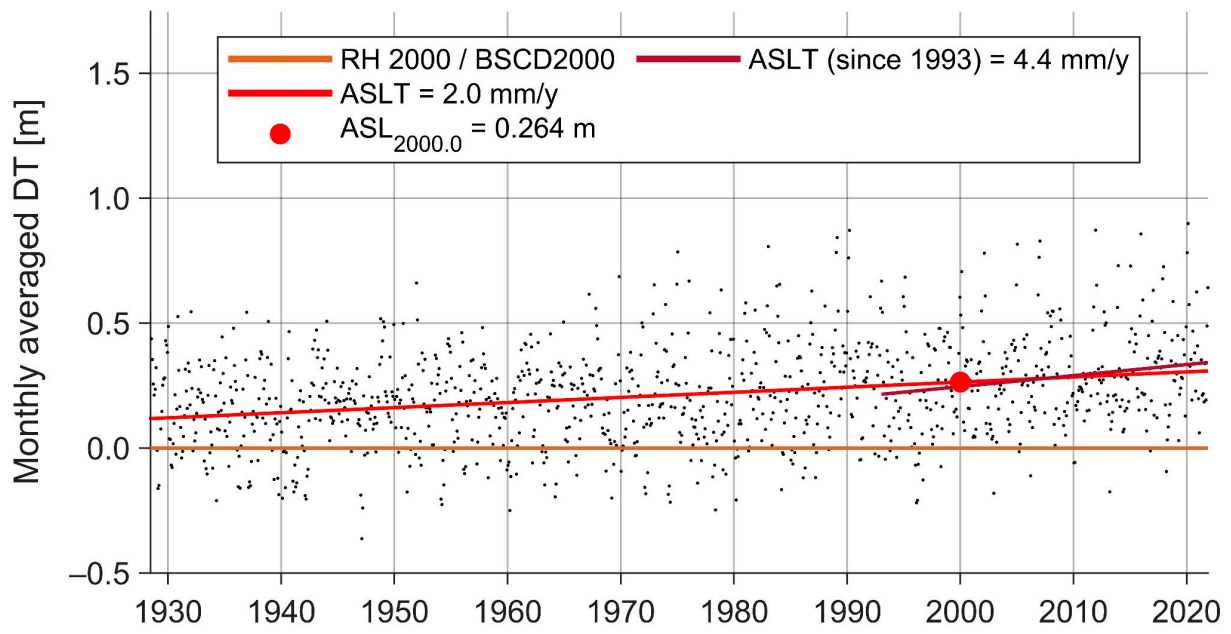

(c)

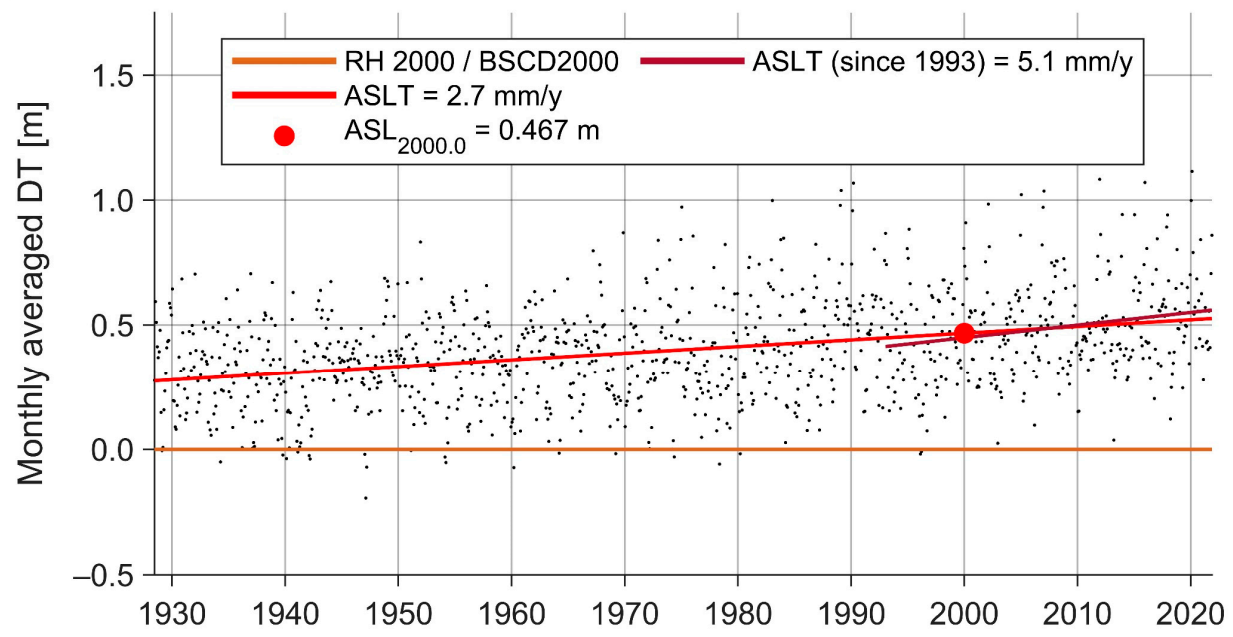

Figure 4. Monthly averaged (a) relative and (b) absolute DT of Ratan TG (cf. Figure 2 for its location) and the estimated sea level trends. In (c) are presented absolute DT and the estimated sea level trends containing purposefully induced errors (i.e., $V L M_{\text {geocentric }}$ and an arbitrary reference epoch 1980.0 are used). 
(a)

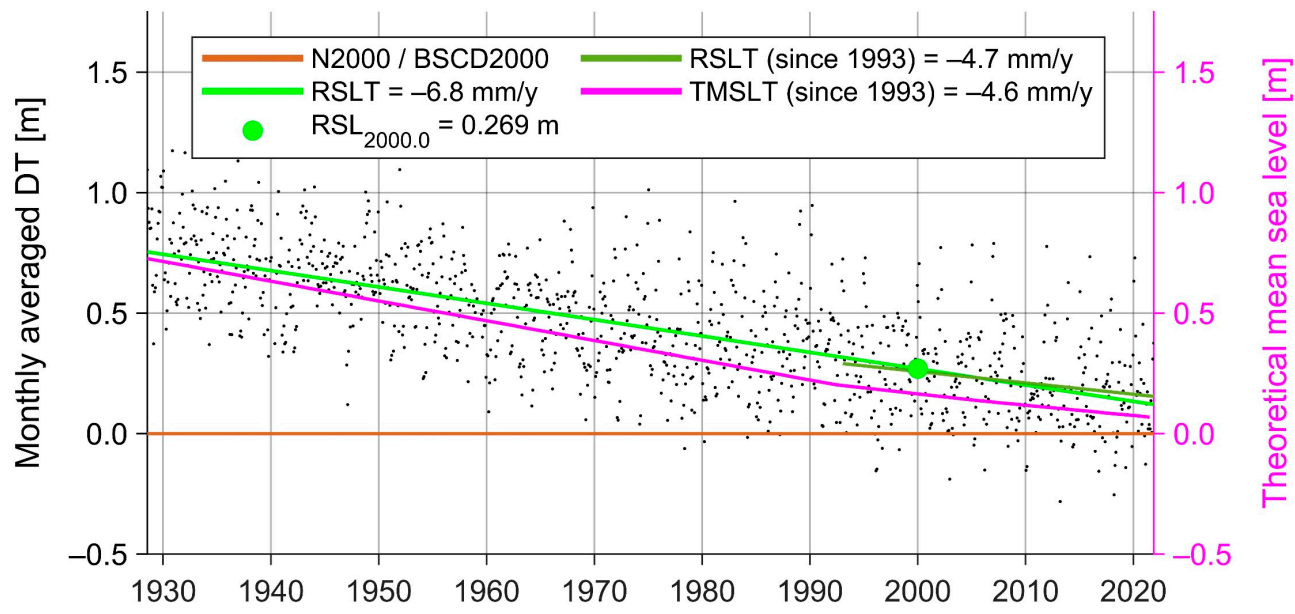

(b)

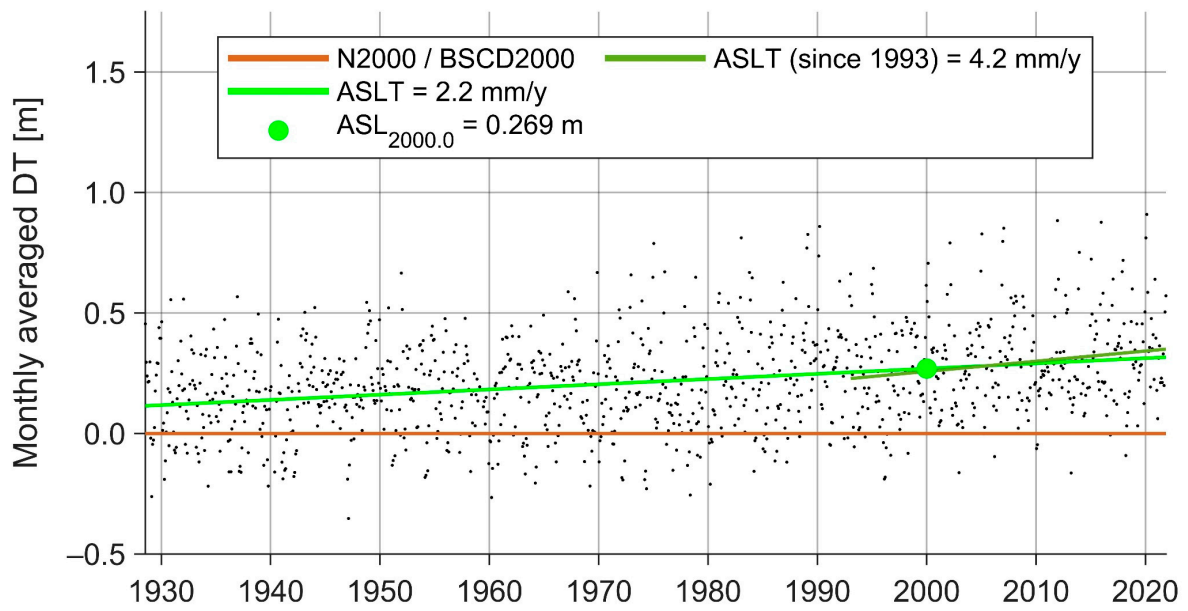

(c)

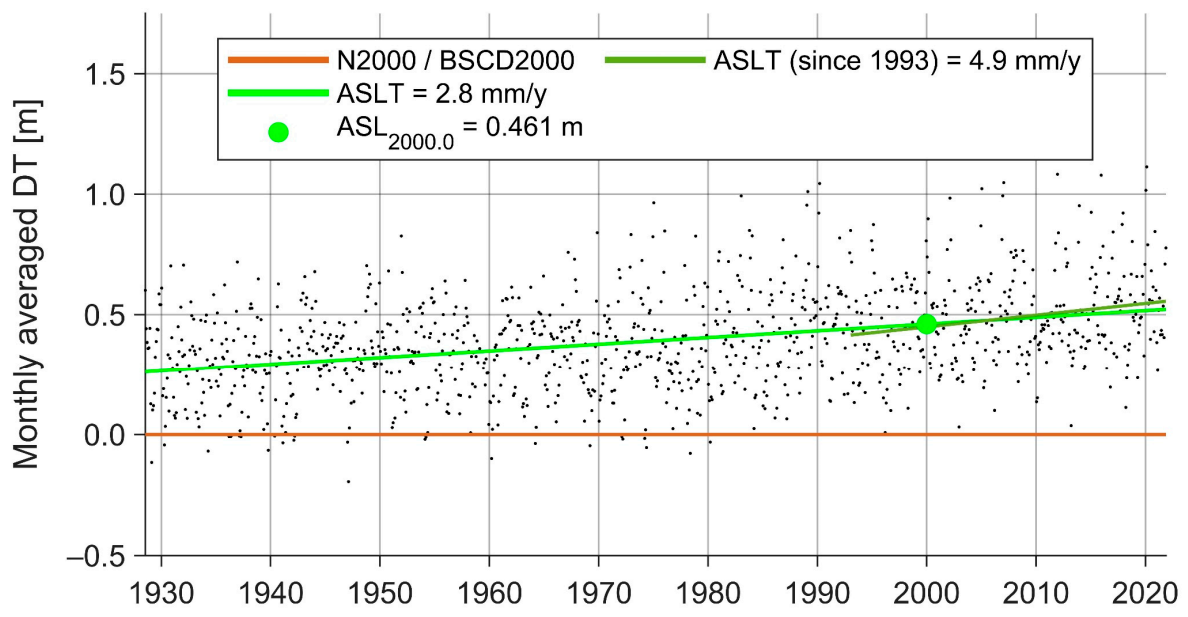

Figure 5. Monthly averaged (a) relative and (b) absolute DT of Pietarsaari TG (cf. Figure 2 for its location) and the estimated sea level trends. In (c) are presented absolute DT and the estimated sea level trends containing purposefully induced errors (i.e., $V L M_{\text {geocentric }}$ and an arbitrary reference epoch 1980.0 are used). 
(a)



(b)

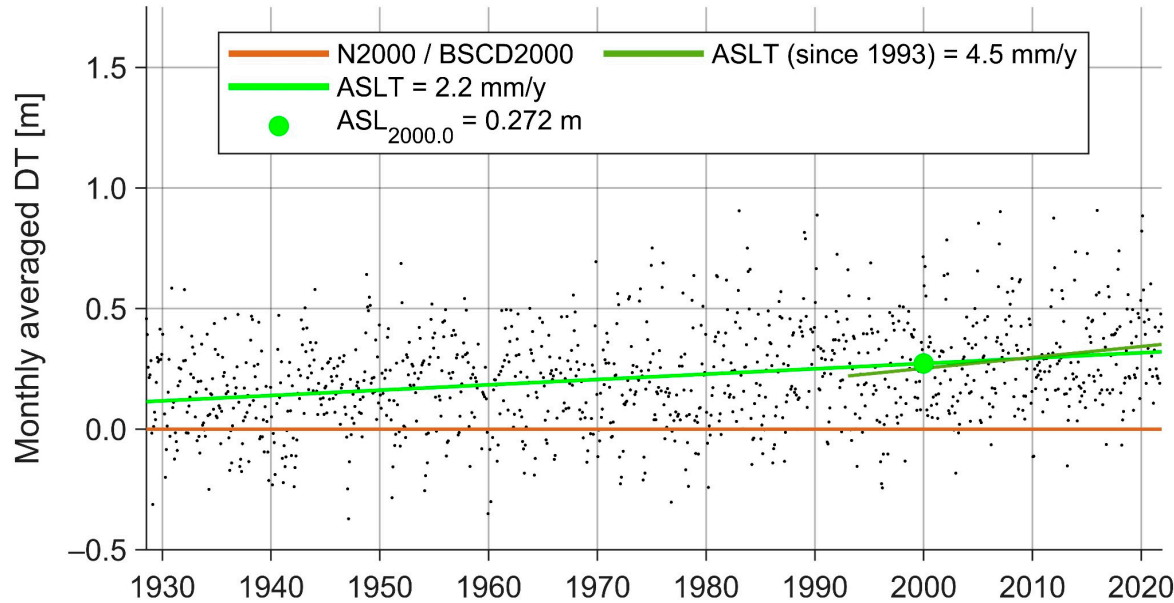

(c)

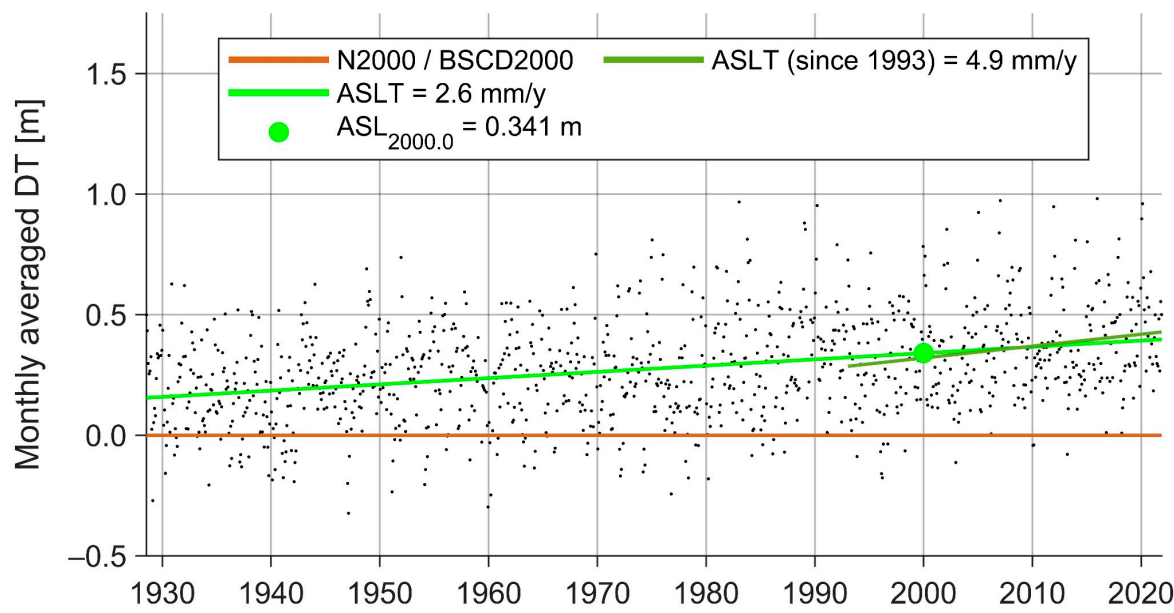

Figure 6. Monthly averaged (a) relative and (b) absolute DT of Hamina TG (cf. Figure 2 for its location) and the estimated sea level trends. In (c) are presented absolute DT and the estimated sea level trends containing purposefully induced errors (i.e., $V L M_{\text {geocentric }}$ and an arbitrary reference epoch 1980.0 are used). 
Initially, the Finnish TG data shown in Figures 5a and 6a are not given relative to the N2000 height system but to the described theoretical mean sea level estimates instead. Note that such estimates are provided not only for the N2000 but also for older Finnish height systems (e.g., N60). Thus, the TG readings can be transformed into a suitable height system using respective height system associated theoretical mean sea level estimates (Figures 5a and 6a show N2000 associated values [67]).

\section{Treatment of Marine GNSS Measurements for Vertical Land Motion}

Over the past few decades, a relatively dense network of GNSS-CORS has been established in Northern Europe to monitor deformations in geodetic networks and provide reliable real-time network service for GNSS measurements. For Estonia, Finland, and Sweden, the national GNSS-CORS networks are named ESTPOS [68,69], FinnRef [70,71] and SWEPOS [45,72], respectively (Table 2). Figure 2 shows national GNSS-CORS belonging to the EUREF Permanent GNSS Network [73].

Table 2. National GNSS networks, corresponding $t_{0}$ and the number of active GNSS-CORS (in 2021) managed by national surveying authorities (Figure 2 shows GNSS-CORS that also belong to the EUREF Permanent GNSS Network).

\begin{tabular}{ccccc}
\hline Country & GNSS-CORS Network & $\boldsymbol{t}_{0}{ }^{1}$ & Number of GNSS Stations & Managing Authority \\
\hline Estonia & ESTPOS & 1997.56 & 29 & Estonian Land Board (ELB) \\
\hline Finland & FinnRef & 1997.0 & 47 & $\begin{array}{c}\text { National Land Survey of } \\
\text { Finland (NLS) }\end{array}$ \\
\hline Sweden & SWEPOS & 1999.5 & $68+406^{2}$ & Lantmäteriet \\
\hline
\end{tabular}

${ }^{1}$ Mean epochs of GNSS measurements for realizing national reference frames. The epochs apply for vertical components only since horizontal coordinates were transferred to the epoch 1989.0 for national implementations of the European Terrestrial Reference System 1989. This implies that the epochs for intraplate deformations are $t_{0}$ and for plate tectonics 1989.0. ${ }^{2}$ Class A + Class B accuracy $(1 \mathrm{~cm}$ at any given time and at the epoch of reference observations, respectively) national GNSS stations.

As was mentioned in the introduction, the GNSS stations are often used to estimate GNSS velocities, for example, to remove VLM from the relative TG-based sea level time series. The GNSS-CORS that belong to the national networks have relatedly been included in relevant research to estimate GNSS velocities and compile VLM models [22,74-76]. However, as further discussed in the introduction, the GNSS records/measurements may similarly require consideration for VLM in marine applications since the measurements are forced to the reference epoch $t_{0}$ (i.e., the coordinates of CORS are fixed to the defining epoch). Although sea level trends contain the GIA-induced geoid change, the general trend of VLM does not influence the sea level (e.g., compare the VLM rate to geoid change in Figure 2). Thus, discrepancies may be introduced by referring GNSS measurements to a reference epoch.

To utilize marine GNSS data, for instance, to validate satellite altimetry determined sea surface heights, the effect of VLM can be included by estimating new CORS coordinates at an observation epoch (considering only the impact of VLM) or by correcting measurements retrospectively for VLM occurring at the CORS. In the latter case, the determination of GNSS-based heights can be expressed in a simplified (assuming ellipsoidal heights and that a single reference station is used) manner as:

$$
h_{1}(\varphi, \lambda, t)=h_{0}\left(\varphi_{R S}, \lambda_{R S}, t_{0}\right)+d h(t)+V L M_{g e o c e n t r i c}\left(\varphi_{R S}, \lambda_{R S}\right) \cdot\left(t-t_{0}\right),
$$

where $h_{0}$ is an ellipsoidal height of a reference station at a reference epoch $t_{0}$ (Table 2 lists $t_{0}$ for Estonian, Finnish, and Swedish GNSS-CORS), $d h$ represents an estimated height difference between a reference station and measurement at observation epoch $t$ and $V L M$ denotes the VLM rate at a reference station (also refer to Figure 1). Since satellite altimetry determined sea surface heights and GNSS measurements are given relative to the reference 
ellipsoid, $V L M_{\text {geocentric }}$ is used. Both satellite altimetry results and GNSS-based ellipsoidal heights $h_{1}$ hence, contain the geoid change.

However, ellipsoidal heights $h_{1}$ are incompatible with the national height systems and BSCD2000. By following the definition of GNSS reference frames, the VLM correction is:

$$
h_{2}\left(\varphi, \lambda, t, t_{0}\right)=h_{0}\left(\varphi_{R S}, \lambda_{R S}, t_{0}\right)+d h(t)+\left[V L M_{\text {geocentric }}\left(\varphi_{R S}, \lambda_{R S}\right)-V L M_{\text {geocentric }}(\varphi, \lambda)\right] \cdot\left(t-t_{0}\right)
$$

where ellipsoidal heights $h_{2}$ follow VLM changes of the sea bottom. Equation (10) represents the standard approach where the measurements are forced to the reference epoch $t_{0}$. Therefore, ellipsoidal heights $h_{2}$ contain an offset relative to the actual ellipsoidal sea surface heights (cf. dashed blue line in Figure 1) but are useful for navigational purposes. Since depths are given relative to BSCD2000, Equation (10) ensures safe navigation through accurate GNSS-based surveillance of the vessels' under keel clearance (i.e., although sea level trends do not follow VLM directly, sea bottom does).

By subtracting compatible geoid model heights from $h_{2}$, relative DT is obtained, which can be converted to absolute DT by Equation (5). This consideration allows the following modification of Equation (10):

$h_{3}\left(\varphi, \lambda, t, t_{0}\right)=h_{0}\left(\varphi_{R S}, \lambda_{R S}, t_{0}\right)+d h(t)+\left[V L M_{\text {geocentric }}\left(\varphi_{R S}, \lambda_{R S}\right)-G C(\varphi, \lambda)\right] \cdot\left(t-t_{0}\right)$

where GC represents geoid change. The resulting ellipsoidal heights $h_{3}$ represent approximately (i.e., geoid change subtracted) the actual sea surface heights and are consistent with the national height systems and BSCD2000 (cf. solid blue line in Figure 1). By subtracting compatible geoid model heights from $h_{3}$, absolute DT is obtained. Such sea surface heights are suitable for validating marine geoid models following the approaches of $[24,25]$ (a similar approach is also presented in the following numerical example, but sea surface heights are validated instead). Note that similar to the tide gauge data treatment, the correctness of resulting marine GNSS measurements depends too on careful choice of the vertical land motion reference surface and the reference epoch (recall the examples that deliberately introduced errors to the TG data in Section 2.3; cf. Figures 4c, $5 c$ and $6 c$ ).

\subsection{A Numerical Example}

In September 2021, a shipborne GNSS campaign (length of 98 km, cf. Figure 2) was conducted. The first data processing results are now examined to provide a numerical example of marine GNSS surveys. The example presents the derivation and validation of GNSS determined sea surface heights. As the main focus here is on applying the VLM correction, the GNSS data processing and analysis are only described in general terms.

The collected $1 / 30 \mathrm{~Hz}$ shipborne GNSS data was post-processed relative to three ESTPOS reference stations (MUS2, KUSA, and VERG, cf. [68] and Figure 2) by employing the commercial Trimble Business Centre software (version 5.52). The standard data processing scheme was utilized, meaning that GNSS-CORS coordinates that refer to the reference epoch (1997.56 for the vertical component, cf. Table 2) were used. Similarly, to [24,51], the closest GNSS-CORS was always employed for a GNSS data point computation (Trimble Business Centre allows only one base station at a time for kinematic data post-processing). Precise GNSS ephemerides were incorporated into post-processing. The resulting data accuracy of such CORS-based post-processing depends heavily on the baseline length (between a GNSS measurement and CORS), which for this campaign remained relatively short, being $20.1 \mathrm{~km}$ by average and $29.4 \mathrm{~km}$ at most. To an extent, the a priori accuracy estimates for the resulting ellipsoidal heights output by the software can be considered an accuracy indicator. For these ellipsoidal heights, the a priori accuracy was estimated at $2.9 \mathrm{~cm}$ by average with a standard deviation of $0.4 \mathrm{~cm}$, indicating relatively stable post-processing performance (high standard deviation can suggest unwanted erratic behavior).

A total station survey was conducted to coordinate the used GNSS antennas (four in total) in the vessel's local system (i.e., locations of GNSS antennas relative to the vessel's railing on both sides). Due to the swaying of the vessel, each point was measured 
carefully six times. The standard deviation estimates (based on six measurements) generally remained within a centimeter of the vertical coordinate components. Averages of six measurements were used as the final coordinates. Tape measurements were then used to determine heights from the sea surface to the vessel's railing (from multiple measuring points). Since the sea surface is ever-changing and the vessel swayed during measurements, but the tape measurements are also subjective (surveyor must assess the optimal measure from moving sea surface), these measures likely contain a relatively large error component. The accuracy of tape measurements is expected to remain within $5 \mathrm{~cm}$. Using these total station and tape measurements, the post-processed GNSS antennas' ellipsoidal heights were reduced into instantaneous sea surface heights, which remained relative to the reference ellipsoid.

Note that such shipborne determined instantaneous sea surface heights are rather noisy due to marine conditions (i.e., waves) and vessel's high-frequency attitude changes (e.g., pitch and roll motions). The latter can be estimated and removed from data using three or more GNSS antennas $[24,77,78]$. Here, the method developed by [24] was employed-the sea surface heights from three antennas were computed jointly to the location of the vessel's stable mass center. Such an approach allows to eliminate (or at the very least significantly reduce) the vessel's high-frequency attitude changes from the joint sea surface height solution. Since 4 antennas were available, a total of 4 different solutions could be computed. As a solution required three antennas (i.e., three points define a plane), the unused fourth one could be used for validation purposes. Based on three used antennas, it was possible to estimate heights (at each GNSS observation epoch $t$ ) for the unused fourth antenna (i.e., using the defined plane). The resulting estimates were then compared to the actual measurements of the fourth antenna. Such comparisons resulted in discrepancies that represent height determination accuracy. The 4 (one for each solution) standard deviation estimates of these discrepancies are 2.8, 2.6, 2.9, and $3.1 \mathrm{~cm}$, indicating a good performance of height determination (also notice that these estimates agree well with the mean a priori estimate of $2.9 \mathrm{~cm}$ ). The average discrepancies for these 4 solutions are $0.7,-0.6,0.7$, and $-0.7 \mathrm{~cm}$, suggesting a successful reduction of post-processed ellipsoidal heights to the sea surface by total station and tape measurements (i.e., all 4 antennas are approximately on the same plane after the reduction). The final instantaneous sea surface heights were then estimated as an average of the 4 solutions at each GNSS observation epoch $t$.

The obtained instantaneous sea surface heights are presented in Figure $7 \mathrm{~b}$ as red dots. Notice, however, that the results still contain some noise and require additional corrections (e.g., see the jump in the profile between GPS time 5.59 to $5.64 \times 10^{5} \mathrm{~s}$ ). Furthermore, the validation of the results demands consideration for the ever-changing DT and needs geoidal heights from an independent source (e.g., a suitable geoid model).

\subsubsection{Derivation of Offshore Dynamic Topography}

Although TGs in the Baltic Sea are modern and capable of high measurement accuracy, they are generally sparsely distributed and restricted spatially to land-bound coastal locations (cf. Figure 2). Hydrodynamic models that can provide high spatial and temporal (hourly) resolution for DT are thus appealing alternative data sources. These models, however, usually refer to arbitrary vertical datums (due to free surface assumption), which may result in a bias relative to the used height systems $[3,25,30,79,80]$. Furthermore, such a dynamic bias changes temporally and spatially, whereby the bias has a long-wavelength nature $[3,81]$. Due to this, the dynamic bias cannot be eliminated by a simple constant value but must be estimated in both the temporal and spatial domains instead. As the Baltic Sea region TGs are rigorously connected to a unified height system (cf. Section 2.2), they can be used to estimate the dynamic bias contained within a hydrodynamic model. 
(a)

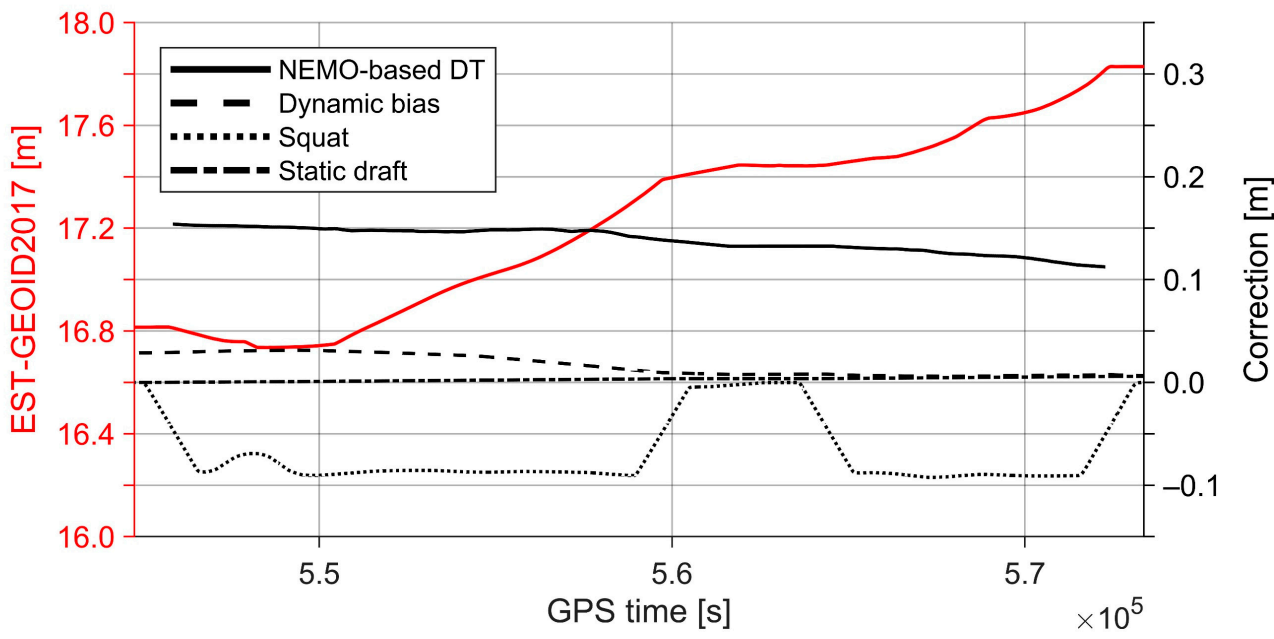

(b)

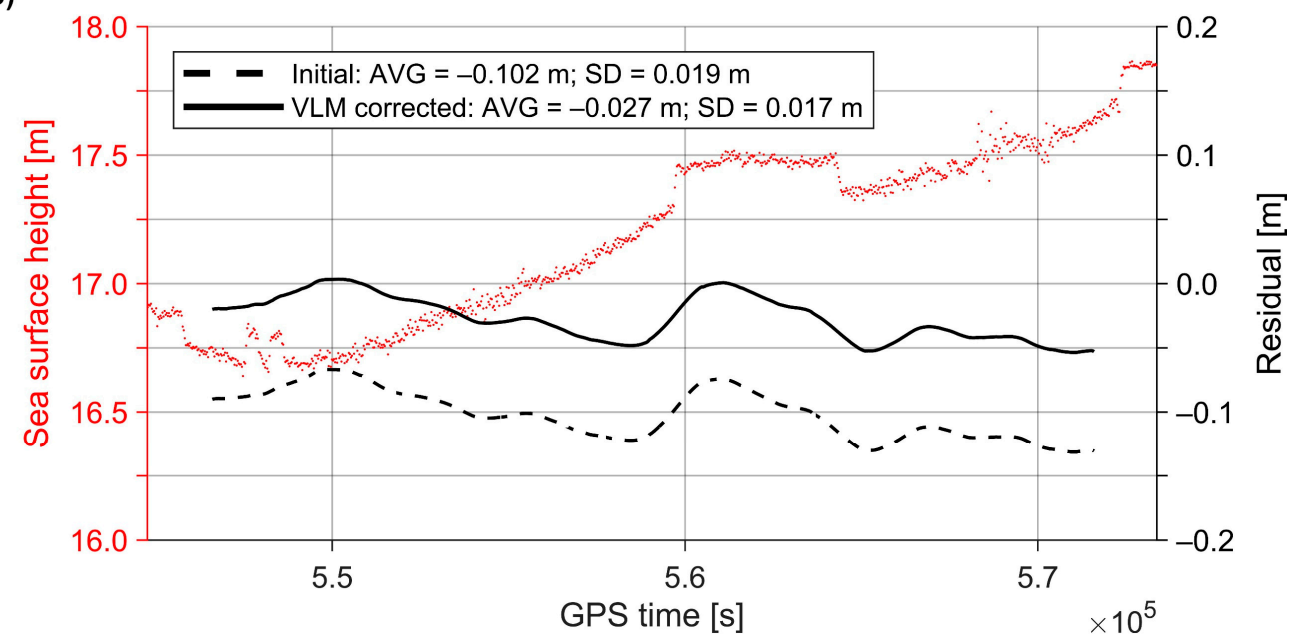

Figure 7. The (a) corrections applied to the GNSS profile and (b) residuals $\left(r_{C}\right)$ of the GNSS profile (after removing geoidal heights and DT, as well as applying the vessel-related corrections), where average and standard deviation of residuals are denoted by AVG and SD, respectively. The red dots in (b) represent instantaneous ellipsoidal sea surface heights.

Thus, the method developed by $[3,25]$ was employed for estimating the dynamic bias of the NEMO-Nordic hydrodynamic model $[82,83]$ that was used for deriving offshore DT (Figure 7a) during the examined shipborne GNSS campaign. Hourly readings from all the Estonian and Finnish TG stations in the Gulf of Finland (cf. Figure 2) were utilized, whereby the $1 \mathrm{~cm}$ discrepancy between EH2000 and N2000 (cf. Section 2.1) was subtracted from the readings of Finnish TGs (since all other datasets refer to EH2000). After correcting the TG readings for VLM according to Equation (5) (note that the TG data remains in zero-tide concept), the bias values were estimated at the TG locations for each hour. The difference with the method in $[3,25]$ is that instead of an exact interpolator, the least-squares collocation was used to grid the hourly bias values with the hydrodynamic model resolution. The resulting dynamic bias estimates are shown in Figure $7 a$.

\subsubsection{Determination of Residuals}

Since the determined sea surface heights still contain noise (Section 3.1) due to heave motion caused by waves, a low-pass filter needs to be applied. This study employed a low-pass filter that combines moving median and average [51]. The filter window of 51 measurements appraised suitable (i.e., filtered data has a similar signal frequency to 
the geoid) by [24] was adopted. However, instead of filtering sea surface heights (SSH) directly, the GNSS determined sea surface heights were first reduced by the derived DT from the NEMO-Nordic hydrodynamic model (in Section 3.1.1) and by geoidal heights $(N)$ :

$$
r_{U C}(\varphi, \lambda, t)=S S H(\varphi, \lambda, t)-[D T(\varphi, \lambda, t)-D B(\varphi, \lambda, t)]-N(\varphi, \lambda),
$$

where DT denotes NEMO-based DT and DB is the estimated dynamic bias. Then, the resulting residuals $\left(r_{U C}\right)$ were filtered instead. The benefit of such an approach is that the geoid slope (and DT slope) does not contaminate the filtering results (depending on data temporal resolution, the filtering window may be several kilometers long). Here, the Estonian national high-resolution geoid model EST-GEOID2017 [84] was used (Figure 7a).

Finally, vessel-related squat and static draft corrections are needed. For this study, both were estimated empirically from multiple shipborne GNSS campaigns (conducted with the same vessel). The squat effect causes the vessel to sail deeper. In deeper open waters, the squat is a function of the vessel's velocity and dimensions (in shallow waters, the water depth also has an impact) [85]. During some of the GNSS campaigns, the vessel occasionally stopped, which allowed relating the vessel's velocity to the height changes between a stationary and moving vessel (by utilizing filtered residuals $\left(r_{U C}\right)$ over distances of up to $3 \mathrm{~km}$ ). Since squat is approximately a quadratic function of velocity $[85,86]$ (the vessel's dimensions are constants, and the surveys were generally conducted in deep waters at speed around 9 knots), it was estimated as least-squares fit of a second-order polynomial to the empirical data. The squat correction as a function of the vessel's velocity [squat $(v)$ ] is shown in Figure 7a.

Due to fuel consumption, the static draft causes the vessel to float upwards gradually. The lowest/highest estimates of the static draft are correspondingly at the time of harbor departure/arrival. It was thus estimated from differences in tape measurements that were conducted before and after shipborne GNSS campaigns. Since tape measurements may contain errors in the range of static draft itself, all the empirical data was considered altogether. The static draft was then estimated as a distance-related linear trend. The static draft correction as a function of distance [static draft(s)] is shown in Figure 7a. After estimating the vessel-related corrections, the final corrected residuals $\left(r_{C}\right)$ were calculated as:

$$
r_{C}(\varphi, \lambda, t)=r_{U C}(\varphi, \lambda, t)-\operatorname{squat}(v)-\text { static draft }(s) .
$$

\subsubsection{Correction for Vertical Land Motion}

In the land uplift regions, the neglected VLM correction may yield lower than actual sea surface heights (the sea surface heights are artificially suppressed downwards by utilizing CORS coordinates of the reference epoch). It can relatedly be noticed that the final corrected residuals $\left(r_{C}\right)$ contain a $-10.2 \mathrm{~cm}$ average discrepancy (see the dashed line in Figure $7 \mathrm{~b}$ ). The results were thus corrected for VLM occurring at the ESTPOS reference stations (according to Equation (11)), employed for GNSS post-processing, using the NKG2016LU model. Note that VLM correction is added to GNSS-based heights right after post-processing, and then the afore-described steps are repeated. As a result, the average discrepancy improves to $-2.7 \mathrm{~cm}$ (see the solid line in Figure $7 \mathrm{~b}$ ). In addition, the standard deviation estimate improves from $1.9 \mathrm{~cm}$ to $1.7 \mathrm{~cm}$ due to the removal of the VLMinduced slope. Note that at MUS2 (westernmost used ESTPOS station), the VLM rate is $3.2 \mathrm{~mm} / \mathrm{y}\left(\sigma_{V L M}=0.16 \mathrm{~mm} / \mathrm{y}\right)$ and at VERG (easternmost used ESTPOS station) $2.9 \mathrm{~mm} / \mathrm{y}$ $\left(\sigma_{V L M}=0.28 \mathrm{~mm} / \mathrm{y}\right)$, which results in an approximately $6.0 \mathrm{~mm}$ west-east directional slope (since epoch 1997.56 to the time of the campaign) in the initial GNSS profile (i.e., the profile without VLM correction).

After correcting for VLM, the remaining residuals shown in Figure $7 \mathrm{~b}$ originate from several sources. These are errors in the total station, tape, GNSS, and TG measurements, estimated corrections, and deficiencies in the used VLM, hydrodynamic and geoid models. Considering the large variety of different datasets involved, the obtained results $(1.7 \mathrm{~cm}$ standard deviation and $-2.7 \mathrm{~cm}$ mean residual) indicate an excellent performance of 
the shipborne GNSS measurements. Finally, the geoid and DT signals can be restored on the derived (and VLM corrected) residuals $r_{C}$, resulting in sea surface heights that approximately represent the actual sea surface (excluding geoid change) at the time of the shipborne GNSS campaign.

\section{Discussion}

In the Baltic Sea region, a strong GIA-induced VLM signal deforms the TG and geodetic networks, the effect of which also appears in the TG and GNSS records. Thus, to obtain research appropriate datasets and provide required consistency between them, it is necessary to account for the occurring VLM by utilizing either a suitable VLM model or employing space-geodetic techniques. The current paper has described in Section 2 the use of VLM correction on the TG time series with relevance to the BSCD2000. Additionally, Section 3 explained how marine GNSS measurements might similarly require consideration for VLM. The described principles were illustrated with numerical examples that, among expected results, also presented deliberately erroneous outcomes to demonstrate how mistakes (or neglect in the marine GNSS case) in applying the VLM correction may lead to data misinterpretation.

From the previous discussions and numerical examples, it is evident that, besides introducing significant errors to TG or GNSS datasets through the improper handling of VLM correction, these errors can also propagate to further data applications. Some potential error sources are, for example, the wrong choice of reference surface or epoch for VLM correction. Take, for instance, the TG corrected (i.e., geoid referred) hydrodynamic modelbased DT described in Section 3.1.1 (the term within square brackets in Equation (12)), which can be used to study offshore DT. Since DT is defined as a separation between sea surface heights and the geoid, geoid rise in the Baltic Sea region needs to be considered (i.e., VLM leveled must be used for correcting TG data, cf. Equation (5)). Although geoid rise according to NKG2016LU is only in the range of $0.16 \mathrm{~mm} / \mathrm{y}$ to $0.66 \mathrm{~mm} / \mathrm{y}$ for the Estonian, Finnish, and Swedish TGs (Figure 2), the changes add up in time. For 2021, the geoid rise would be in the range of 0.3 to $1.4 \mathrm{~cm}$ relative to the reference epoch 2000.0. Note, however, that even larger errors could be introduced through inconsistent use of the reference epoch for correcting TG data for VLM (recall the TG data examples in Section 2.3). These errors in the TG data will then propagate similarly to the derived offshore DT. Although the geoid referred hydrodynamic model-based DT can reveal, for instance, mean DT patterns that are not evident by considering the initial hydrodynamic model-based DT [3], the described error sources may lead to a misinterpretation of the results. Importantly, the oceanographic applications also require TG data conversion from the initial zero-tide concept to the mean-tide (cf. Equation (4)) because the zero-tide concept generates a tilt in the DT estimates.

Furthermore, the afore-described geoid referred DT can be used for other applications besides studying the patterns of mean DT. Since conventional precise GNSS-leveling control points cannot be established offshore, the derived DT combined with marine GNSS measurements can be used to validate marine geoid models [24,52,55]. Note that satellite altimetry [87] or airborne laser scanning [25] measurements of sea surface heights can be used similarly. Alternatively, the same datasets may reveal deficiencies in the estimated DT [88]. Such a validation principle is also presented in Section 3.1's numerical example. Yet, in these cases, multiple data sources are used that require consideration for VLM (e.g., by comparing Tables 1 and 2 notice that $t_{0}$ can differ for TG and GNSS data). The potential sources of errors are thus twofold.

It should be mentioned, however, that satellite altimetry is an exception. Although the determined sea surface heights contain the GIA-induced geoid change, the general VLM trends do not contaminate these data (cf. Figure 1; also see Figure 2 for a comparison between VLM and geoid change rates). The GIA-induced geoid change can be obtained from a suitable geoid change model that usually accompanies a GIA model (for the Baltic Sea region, the NKG2016LU VLM model provides geoid change). Concerning the current study, 
also bear in mind that GNSS-based techniques are a common approach for validating and calibrating satellite altimetry results [89-91]. Hence, consideration of the VLM occurring at the GNSS reference stations is necessary for consistent comparisons (cf. Equation (9)). The validation may otherwise result in a misinterpretation due to neglected VLM that can contaminate the GNSS-based sea surface heights reference data (cf. Section 3.1.3). On the other hand, geoid change corrected satellite altimetry records can also be used for independent validations and inter-comparisons. For instance, to assess TG-based absolute sea level trends (i.e., VLM corrected TG trends, e.g., by GNSS time series). The synergy between various datasets can therefore reveal patterns (e.g., in VLM) that may otherwise remain unnoticed.

\section{Conclusions}

Implementation of the BSCD2000, a common height reference for the Baltic Sea region, has been initiated to effectively use GNSS methods for accurate navigation and real-time offshore surveying. Offshore, BSCD2000 will be realized through GNSS and geoid modeling, while onshore, BSCD2000 will be compatible with the national height system realizations of the Baltic Sea countries (e.g., EH2000, N2000, and RH 2000) and will coincide with national geoid models to allow seamless height transitions. Another principal component of BSCD2000 is that the TG stations are rigorously connected to the national height systems via precise leveling. Since the zero values of TGs coincide with the BSCD2000, the contemporary TG readings can be expressed directly as DT relative to the geoid at the system reference epoch. Such a common system around the Baltic Sea can provide new geodetic and oceanographic research opportunities. However, it is crucial to consider that the TG and geodetic networks in the Baltic Sea region are deforming due to VLM, the effect of which also appears in the TG and GNSS records.

Thus, this contribution has reviewed the treatment of TG time series for VLM and outlined potential error sources for utilizing TG data relative to a common reference (e.g., BSCD2000 in this study). The described principles were illustrated with numerical examples that, among expected results, also simulated deliberately erroneous outcomes. It was shown that the wrong choice of reference surface for VLM correction (i.e., reference ellipsoid instead of geoid) could lead to a severe misinterpretation of the climate-related sea level trend signal. For instance, instead of the expected sea level rise trend of $2.0 \mathrm{~mm} / \mathrm{y}$ (an average annual sea level rise over the examined 94 years) at the Ratan TG station (cf. Figure $4 \mathrm{~b}$ ), a trend of $2.7 \mathrm{~mm} / \mathrm{y}$ (cf. Figure $4 \mathrm{c}$ ) was obtained instead due to the inclusion of GIA-induced geoid change. Alternatively, by wrongly correcting the TG data relative to an arbitrary reference epoch 1980.0 (instead of 2000.0), the obtained mean DT estimate (at epoch 2000.0 according to the fitted linear trend) at the Pietarsaari TG station was $0.461 \mathrm{~m}$ instead of $0.269 \mathrm{~m}$ (Figure 5). At the same time, an estimate of $0.341 \mathrm{~m}$ was obtained at the Hamina TG instead of the expected $0.272 \mathrm{~m}$ (Figure 6). These results demonstrated how inconsistent use of the reference epoch could lead to significant errors in estimating absolute mean DT.

Similar consideration was given to marine GNSS measurements that likewise require VLM correction for some marine applications. A numerical example describing the validation of shipborne GNSS determined sea surface heights was provided to illustrate the described principles. It was shown that the application of VLM correction improves the average residual from $-10.2 \mathrm{~cm}$ to $-2.7 \mathrm{~cm}$ (Figure 7 ). In addition, the standard deviation estimate improved from $1.9 \mathrm{~cm}$ to $1.7 \mathrm{~cm}$ due to the removal of the VLM-induced slope. Hence, in the VLM-affected regions, the described principles are essential for facilitating consistency between various data sources (e.g., TG, GNSS, and satellite altimetry) and reference surfaces (e.g., BSCD2000). 
Author Contributions: Conceptualization, S.V., J.Å., A.E. and M.P.; methodology, S.V.; software, S.V.; validation, S.V.; formal analysis, S.V.; investigation, S.V.; resources, S.V., J.A., A.E. and M.P.; data curation, S.V., A.E. and M.P.; writing—original draft preparation, S.V.; writing-review and editing, S.V., J.Å., A.E. and M.P.; visualization, S.V.; supervision, A.E.; project administration, A.E.; funding acquisition, A.E. All authors have read and agreed to the published version of the manuscript.

Funding: This research was funded by the Estonian Research Council grant "Development of an iterative approach for near-coast marine geoid modelling by using re-tracked satellite altimetry, in situ and modelled data", grant number PRG330.

Institutional Review Board Statement: Not applicable.

Informed Consent Statement: Not applicable.

Data Availability Statement: The used hourly Swedish and Finnish TG data can be downloaded from SMHI and FMI webpages $[60,61,67]$. The monthly mean sea level data for Pietarsaari and Hamina TGs can be downloaded from the PSMSL webpage [62,63]. The employed NKG2016LU VLM model is provided by Lantmäteriet (on behalf of the Nordic Geodetic Commission-NKG): https: / www. lantmateriet.se/en/maps-and-geographic-information/gps-geodesi-och-swepos/Referenssystem/ Landhojning/ (accessed on 22 December 2021).

Acknowledgments: Colleagues from the Marine Systems Institute at the Tallinn University of Technology and the crew of the research surveying vessel Salme are thanked for assisting in conducting shipborne GNSS campaigns. A special thanks to OÜ Geosoft, who provided the used GNSS equipment. Aive Liibusk is thanked for post-processing the used shipborne GNSS data. The Estonian Environment Agency provided the used Estonian TG data. A special thanks to the Swedish Meteorological and Hydrological Institute for their cooperation in obtaining NEMO-Nordic model data. The three anonymous reviewers are thanked for their contribution to the quality of the manuscript.

Conflicts of Interest: The authors declare no conflict of interest.

\section{References}

1. Spada, G.; Galassi, G. New estimates of secular sea level rise from tide gauge data and GIA modelling. Geophys. J. Int. 2012, 191, 1067-1094. [CrossRef]

2. Breili, K.; Simpson, M.J.R.; Nilsen, J.E.Ø. Observed sea-level changes along the Norwegian coast. J. Mar. Sci. Eng. 2017, 5, 29. [CrossRef]

3. Jahanmard, V.; Delpeche-Ellmann, N.; Ellmann, A. Realistic dynamic topography through coupling geoid and hydrodynamic models of the Baltic Sea. Cont. Shelf Res. 2021, 222, 104421. [CrossRef]

4. Watson, C.S.; Legresy, B.; King, M.A. On the uncertainty associated with validating the global mean sea level climate record. Adv. Space Res. 2021, 68, 487-495. [CrossRef]

5. Klos, A.; Kusche, J.; Fenoglio-Marc, L.; Bos, M.S.; Bogusz, J. Introducing a vertical land motion model for improving estimates of sea level rates derived from tide gauge records affected by earthquakes. GPS Solut. 2019, 23, 102. [CrossRef]

6. Denys, P.H.; Beavan, R.J.; Hannah, J.; Pearson, C.F.; Palmer, N.; Denham, M.; Hreinsdottir, S. Sea level rise in New Zealand: The effect of vertical land motion on century-long tide gauge records in a tectonically active region. J. Geophys. Res. Solid Earth 2020, 125, e2019JB018055. [CrossRef]

7. Raucoules, D.; Le Cozannet, G.; Wöppelmann, G.; de Michele, M.; Gravelle, M.; Daag, A.; Marcos, M. High nonlinear urban ground motion in Manila (Philippines) from 1993 to 2010 observed by DInSAR: Implications for sea-level measurement. Remote Sens. Environ. 2013, 139, 386-397. [CrossRef]

8. Fokker, P.A.; van Leijen, F.J.; Orlic, B.; van der Marel, H.; Hanssen, R.F. Subsidence in the Dutch Wadden Sea. Neth. J. Geosci. 2018, 97, 129-181. [CrossRef]

9. Wöppelmann, G.; Marcos, M. Vertical land motion as a key to understanding sea level change and variability. Rev. Geophys. 2016, 54, 64-92. [CrossRef]

10. Santamaría-Gómez, A.; Gravelle, M.; Dangendorf, S.; Marcos, M.; Spada, G.; Wöppelmann, G. Uncertainty of the 20th century sea-level rise due to vertical land motion errors. Earth Planet. Sci. Lett. 2017, 473, 24-32. [CrossRef]

11. Hammond, W.C.; Blewitt, G.; Kreemer, C.; Nerem, R.S. GPS imaging of global vertical land motion for studies of sea level rise. J. Geophys. Res. Solid Earth 2021, 126, e2021JB022355. [CrossRef]

12. Shirzaei, M.; Bürgmann, R. Global climate change and local land subsidence exacerbate inundation risk to the San Francisco Bay area. Sci. Adv. 2018, 4, eaap9234. [CrossRef] [PubMed]

13. Grgić, M.; Bender, J.; Bašić, T. Estimating vertical land motion from remote sensing and in-situ observations in the Dubrovnik area (Croatia): A multi-method case study. Remote Sens. 2020, 12, 3543. [CrossRef]

14. Pfeffer, J.; Allemand, P. The key role of vertical land motions in coastal sea level variations: A global synthesis of multisatellite altimetry, tide gauge data and GPS measurements. Earth Planet. Sci. Lett. 2016, 439, 39-47. [CrossRef] 
15. Steffen, H.; Wu, P. Glacial isostatic adjustment in Fennoscandia-A review of data and modelling. J. Geodyn. 2011, 52, 169-204. [CrossRef]

16. Simpson, M.J.R.; Ravndal, O.R.; Sande, H.; Nilsen, J.E.Ø.; Kierulf, H.P.; Vestøl, O.; Steffen, H. Projected 21st century sea-level changes, observed sea level extremes, and sea level allowances for Norway. J. Mar. Sci. Eng. 2017, 5, 36. [CrossRef]

17. Idžanović, M.; Gerlach, C.; Breili, K.; Andersen, O.B. An attempt to observe vertical land motion along the Norwegian coast by CryoSat-2 and tide gauges. Remote Sens. 2019, 11, 744. [CrossRef]

18. De Biasio, F.; Baldin, G.; Vignudelli, S. Revisiting vertical land motion and sea level trends in the northeastern Adriatic Sea using satellite altimetry and tide gauge data. J. Mar. Sci. Eng. 2020, 8, 949. [CrossRef]

19. Cipollini, P.; Calafat, F.M.; Jevrejeva, S.; Melet, A.; Prandi, P. Monitoring sea level in the coastal zone with satellite altimetry and tide gauges. Surv. Geophys. 2017, 38, 33-57. [CrossRef]

20. Vignudelli, S.; Birol, F.; Benveniste, J.; Fu, L.-L.; Picot, N.; Raynal, M.; Roinard, H. Satellite altimetry measurements of sea level in the coastal zone. Surv. Geophys. 2019, 40, 1319-1349. [CrossRef]

21. Peltier, W.R.; Argus, D.F.; Drummond, R. Space geodesy constrains ice age terminal deglaciation: The global ICE-6G_C (VM5a) model. J. Geophys. Res. Solid Earth 2015, 120, 450-487. [CrossRef]

22. Vestøl, O.; Ågren, J.; Steffen, H.; Kierulf, H.; Tarasov, L. NKG2016LU: A new land uplift model for Fennoscandia and the Baltic region. J. Geod. 2019, 93, 1759-1779. [CrossRef]

23. Siegismund, F.; Köhl, A.; Rummel, R.; Stammer, D. Temporal variations of the marine geoid. J. Geophys. Res. Oceans 2020, 125, e2020JC016433. [CrossRef]

24. Varbla, S.; Ellmann, A.; Delpeche-Ellmann, N. Validation of marine geoid models by utilizing hydrodynamic model and shipborne GNSS profiles. Mar. Geod. 2020, 43, 134-162. [CrossRef]

25. Varbla, S.; Ellmann, A.; Delpeche-Ellmann, N. Applications of airborne laser scanning for determining marine geoid and surface waves properties. Eur. J. Remote Sens. 2021, 54, 557-567. [CrossRef]

26. Ludwigsen, C.A.; Khan, S.A.; Andersen, O.B.; Marzeion, B. Vertical land motion from present-day deglaciation in the wider Arctic. Geophys. Res. Lett. 2020, 47, e2020GL088144. [CrossRef]

27. Simon, K.M.; Riva, R.E.M.; Vermeersen, L.L.A. Constraint of glacial isostatic adjustment in the North Sea with geological relative sea level and GNSS vertical land motion data. Geophys. J. Int. 2021, 227, 1168-1180. [CrossRef]

28. Hünicke, B.; Zorita, E. Statistical analysis of the acceleration of Baltic mean sea-level rise, 1900-2012. Front. Mar. Sci. 2016, 3, 125. [CrossRef]

29. Gräwe, U.; Klingbeil, K.; Kelln, J.; Dangendorf, S. Decomposing mean sea level rise in a semi-enclosed basin, the Baltic Sea. J. Clim. 2019, 32, 3089-3108. [CrossRef]

30. Madsen, K.S.; Høyer, J.L.; Suursaar, Ü.; She, J.; Knudsen, P. Sea level trends and variability of the Baltic Sea from 2D statistical reconstruction and altimetry. Front. Earth Sci. 2019, 7, 243. [CrossRef]

31. Agha Karimi, A.; Bagherbandi, M.; Horemuz, M. Multidecadal sea level variability in the Baltic Sea and its impact on acceleration estimations. Front. Mar. Sci. 2021, 8, 702512. [CrossRef]

32. Passaro, M.; Müller, F.L.; Oelsmann, J.; Rautiainen, L.; Dettmering, D.; Hart-Davis, M.G.; Abulaitijiang, A.; Andersen, O.B.; Høyer J.L.; Madsen, K.S.; et al. Absolute Baltic Sea level trends in the satellite altimetry era: A revisit. Front. Mar. Sci. 2021, 8, 647607. [CrossRef]

33. Suursaar, Ü.; Kall, T. Decomposition of relative sea level variations at tide gauges using results from four Estonian precise levelings and uplift models. IEEE J. Sel. Top. Appl. Earth Obs. Remote Sens. 2018, 11, 1966-1974. [CrossRef]

34. Schwabe, J.; Ågren, J.; Liebsch, G.; Westfeld, P.; Hammarklint, T.; Mononen, J.; Andersen, O.B. The Baltic Sea Chart Datum 2000 (BSCD2000)_Implementation of a common reference level in the Baltic Sea. Int. Hydrogr. Rev. 2020, $23,63-83$.

35. Kollo, K.; Ellmann, A. Geodetic reconciliation of tide gauge network in Estonia. Geophysica 2019, 54, $27-38$.

36. Woodworth, P.L.; Hughes, C.W.; Bingham, R.J.; Gruber, T. Towards worldwide height system unification using ocean information J. Geod. Sci. 2013, 2, 302-318. [CrossRef]

37. Lan, W.-H.; Kuo, C.-Y.; Kao, H.-C.; Lin, L.-C.; Shum, C.K.; Tseng, K.-H.; Chang, J.-C. Impact of geophysical and datum corrections on absolute sea-level trends from tide gauges around Taiwan, 1993-2015. Water 2017, 9, 480. [CrossRef]

38. Amjadiparvar, B.; Rangelova, E.; Sideris, M.G. The GBVP approach for vertical datum unification: Recent results in North America. J. Geod. 2016, 90, 45-63. [CrossRef]

39. Featherstone, W.E.; Filmer, M.S. The north-south tilt in the Australian Height Datum is explained by the ocean's mean dynamic topography. J. Geophys. Res. Oceans 2012, 117, C08035. [CrossRef]

40. Amjadiparvar, B.; Rangelova, E.V.; Sideris, M.G.; Véronneau, M. North American height datums and their offsets: The effect of GOCE omission errors and systematic levelling effects. J. Appl. Geod. 2013, 7, 39-50. [CrossRef]

41. Saaranen, V.; Lehmuskoski, P.; Rouhiainen, P.; Takalo, M.; Mäkinen, J.; Poutanen, M. The new Finnish height reference N2000. In Geodetic Reference Frames; Drewes, H., Ed.; International Association of Geodesy Symposia Book Series (IAG SYMPOSIA); Springer: Berlin/Heidelberg, Germany, 2009; Volume 134, pp. 297-302. [CrossRef]

42. Svensson, R.; Ågren, J.; Olsson, P.-A.; Eriksson, P.-O.; Lilje, M. The new Swedish height system RH 2000 and geoid model SWEN 05LR. In Proceedings of the XXIII International FIG Congress: Shaping the Change, Munich, Germany, 8-13 October 2006.

43. Ågren, J.; Svensson, R. Postglacial Land Uplift Model and System Definition for the New Swedish Height System RH 2000; Lantmäteriet: Gävle, Sweden, 2007. 
44. Vestøl, O. Determination of postglacial land uplift in Fennoscandia from leveling, tide-gauges and continuous GPS stations using least squares collocation. J. Geod. 2006, 80, 248-258. [CrossRef]

45. Kempe, C.; Jivall, L.; Lidberg, M.; Lilje, M. On the management of reference frames in Sweden. In Proceedings of the FIG Working Week 2016: Recovery from Disaster, Christchurch, New Zealand, 2-6 May 2016.

46. EVRS Height Datum Relations. Available online: https://evrs.bkg.bund.de/Subsites/EVRS/EN/Projects/HeightDatumRel/ height-datum-rel.html (accessed on 1 November 2021).

47. EVRF2019. Available online: https://evrs.bkg.bund.de/Subsites/EVRS/EN/EVRF2019/evrf2019.html (accessed on 3 November 2021)

48. Ågren, J.; Strykowski, G.; Bilker-Koivula, M.; Omang, O.; Märdla, S.; Forsberg, R.; Ellmann, A.; Oja, T.; Liepins, I.; Parseliunas, E.; et al. The NKG2015 gravimetric geoid model for the Nordic-Baltic region. In Proceedings of the International Symposium on Gravity, Geoid and Height Systems 2016, Thessaloniki, Greece, 19-23 September 2016. [CrossRef]

49. Ågren, J.; Liebsch, G.; Mononen, J. Specification of the Baltic Sea Chart Datum 2000 (BSCD2000). Available online: http: / / www.bshc.pro/media/documents/CDWG/CDWG+Specification+of+the+Baltic+Sea+Chart+Datum+2000.pdf (accessed on 7 December 2021).

50. Schwabe, J.; Strykowski, G.; Ågren, J.; Ellmann, A.; Varbla, S.; Forsberg, R.; Teitsson, H. Status of the "FAMOS Finalization" /BSCD2000 Geoid. Available online: http:/ /www.bshc.pro/media/documents/CDWG/CDWG13+FAMOS+Finalization+ 2021-09-07.pdf (accessed on 20 January 2022).

51. Varbla, S.; Ellmann, A.; Märdla, S.; Gruno, A. Assessment of marine geoid models by ship-borne GNSS profiles. Geod. Cartogr. 2017, 43, 41-49. [CrossRef]

52. Nordman, M.; Kuokkanen, J.; Bilker-Koivula, M.; Koivula, H.; Häkli, P.; Lahtinen, S. Geoid validation on the Baltic Sea using ship-borne GNSS data. Mar. Geod. 2018, 41, 457-476. [CrossRef]

53. Lu, B.; Barthelmes, F.; Li, M.; Förste, C.; Ince, E.S.; Petrovic, S.; Flechtner, F.; Schwabe, J.; Luo, Z.; Zhong, B.; et al. Shipborne gravimetry in the Baltic Sea: Data processing strategies, crucial findings and preliminary geoid determination tests. J. Geod. 2019, 93, 1059-1071. [CrossRef]

54. Ince, E.S.; Förste, C.; Barthelmes, F.; Pflug, H.; Li, M.; Kaminskis, J.; Neumayer, K.-H.; Michalak, G. Gravity measurements along commercial ferry lines in the Baltic Sea and their use for geodetic purposes. Mar. Geod. 2020, 43, 573-602. [CrossRef]

55. Saari, T.; Bilker-Koivula, M.; Koivula, H.; Nordman, M.; Häkli, P.; Lahtinen, S. Validating geoid models with marine GNSS measurements, sea surface models, and additional gravity observations in the Gulf of Finland. Mar. Geod. 2021, 44, 196-214. [CrossRef]

56. Poutanen, M.; Vermeer, M.; Mäkinen, J. The permanent tide in GPS positioning. J. Geod. 1996, 70, 499-504. [CrossRef]

57. Ihde, J.; Mäkinen, J.; Sacher, M. Conventions for the Definition and Realization of a European Vertical Reference System (EVRS); Version 5.2; Federal Agency for Cartography and Geodesy (BKG): Frankfurt, Germany, 2019.

58. Ihde, J.; Augath, W. European Vertical Reference System (EVRS). In Proceedings of the EUREF Symposium 2000, Tromsø, Norway, 22-24 June 2000.

59. Gruber, T.; Ågren, J.; Angermann, D.; Ellmann, A.; Engfeldt, A.; Gisinger, C.; Jaworski, L.; Marila, S.; Nastula, J.; Nilfouroushan, F.; et al. Geodetic SAR for height system unification and sea level research-observation concept and preliminary results in the Baltic Sea. Remote Sens. 2020, 12, 3747. [CrossRef]

60. SMHI Oceanographic Observations. Available online: https://www.smhi.se/data/oceanografi/ladda-ner-oceanografiskaobservationer /\#param=sealevelrh2000,stations=all (accessed on 4 November 2021).

61. FMI Observations. Available online: https://en.ilmatieteenlaitos.fi/download-observations\#!/ (accessed on 4 November 2021)

62. Permanent Service for Mean Sea Level, Pietarsaari. Available online: https://www.psmsl.org/data/obtaining/stations/194.php (accessed on 24 November 2021).

63. Permanent Service for Mean Sea Level, Hamina. Available online: https://www.psmsl.org/data/obtaining/stations/315.php (accessed on 24 November 2021).

64. Medvedev, I.; Kulikov, E. Low-frequency Baltic Sea level spectrum. Front. Earth Sci. 2019, 7, 284. [CrossRef]

65. Visser, H.; Dangendorf, S.; Petersen, A.C. A review of trend models applied to sea level data with reference to the "accelerationdeceleration debate". J. Geophys. Res. Oceans 2015, 120, 3873-3895. [CrossRef]

66. Douglas, B.C. Global sea rise: A redetermination. Surv. Geophys. 1997, 18, 279-292. [CrossRef]

67. Theoretical Mean Water and Geodetical Height Systems in Finland. Available online: https://en.ilmatieteenlaitos.fi/theoreticalmean-sea-level (accessed on 4 November 2021).

68. Metsar, J.; Kollo, K.; Ellmann, A. Modernization of the Estonian national GNSS reference station network. Geod. Cartogr. 2018, 44, 55-62. [CrossRef]

69. Metsar, J.; Kollo, K.; Ellmann, A.; Rüdja, A.; Pihlak, P. Multi-epoch GNSS campaigns of the national geodetic network in Estonia. Geophysica 2019, 54, 51-60.

70. Koivula, H.; Laaksonen, A.; Lahtinen, S.; Kuokkanen, J.; Marila, S. Finnish permanent GNSS network, FinnRef. In Proceedings of the FIG Working Week 2017: Surveying the World of Tomorrow-From Digitalisation to Augmented Reality, Helsinki, Finland, 29 May-2 June 2017.

71. Koivula, H. Finnish Permanent GNSS Network FinnRef. Ph.D. Thesis, Aalto University, Espoo, Finland, 2019.

72. Lilje, M.; Wiklund, P.; Hedling, G. The use of GNSS in Sweden and the national CORS network SWEPOS. In Proceedings of the FIG Congress 2014: Engaging the Challenges-Enhancing the Relevance, Kuala Lumpur, Malaysia, 16-21 June 2014. 
73. EUREF Permanent GNSS Network. Available online: https://www.epncb.oma.be/_organisation/about.php (accessed on 4 November 2021).

74. Kall, T.; Oja, T.; Kruusla, K.; Liibusk, A. New 3D velocity model of Estonia from GNSS measurements. Est. J. Earth Sci. 2021, 70, 107-125. [CrossRef]

75. Kierulf, H.P.; Steffen, H.; Barletta, V.R.; Lidberg, M.; Johansson, J.; Kristiansen, O.; Tarasov, L. A GNSS velocity field for geophysical applications in Fennoscandia. J. Geodyn. 2021, 146, 101845. [CrossRef]

76. Lahtinen, S.; Jivall, L.; Häkli, P.; Nordman, M. Updated GNSS velocity solution in the Nordic and Baltic countries with a semi-automatic offset detection method. GPS Solut. 2022, 26, 9. [CrossRef]

77. Lavrov, D.; Even-Tzur, G.; Reinking, J. Expansion and improvement of the Israeli geoid model by shipborne GNSS measurements. J. Surv. Eng. 2017, 143, 04016022. [CrossRef]

78. Roggenbuck, O.; Reinking, J. Sea surface heights retrieval from ship-based measurements assisted by GNSS signal reflections. Mar. Geod. 2019, 42, 1-24. [CrossRef]

79. Slobbe, D.C.; Verlaan, M.; Klees, R.; Gerritsen, H. Obtaining instantaneous water levels relative to a geoid with a 2D storm surge model. Cont. Shelf Res. 2013, 52, 172-189. [CrossRef]

80. Rulent, J.; Calafat, F.M.; Banks, C.J.; Bricheno, L.M.; Gommenginger, C.; Green, J.A.M.; Haigh, I.D.; Lewis, H.; Martin, A.C.H. Comparing water level estimation in coastal and shelf seas from satellite altimetry and numerical models. Front. Mar. Sci. 2020, 7,549467. [CrossRef]

81. Lagemaa, P.; Elken, J.; Kõuts, T. Operational sea level forecasting in Estonia. Est. J. Eng. 2011, 17, 301-331. [CrossRef]

82. Hordoir, R.; Axell, L.; Höglund, A.; Dieterich, C.; Fransner, F.; Gröger, M.; Liu, Y.; Pemberton, P.; Schimanke, S.; Andersson, H.; et al. Nemo-Nordic 1.0: A NEMO-based ocean model for the Baltic and North seas-research and operational applications. Geosci. Model Dev. 2019, 12, 363-386. [CrossRef]

83. Kärnä, T.; Ljungemyr, P.; Falahat, S.; Ringgaard, I.; Axell, L.; Korabel, V.; Murawski, J.; Maljutenko, I.; Lindenthal, A.; Jandt-Scheelke, S.; et al. Nemo-Nordic 2.0: Operational marine forecast model for the Baltic Sea. Geosci. Model Dev. 2021, 14, 5731-5749. [CrossRef]

84. Ellmann, A.; Märdla, S.; Oja, T. The $5 \mathrm{~mm}$ geoid model for Estonia computed by the least squares modified Stokes's formula. Surv. Rev. 2020, 52, 352-372. [CrossRef]

85. Barrass, C.B. Ship Design and Performance for Masters and Mates; Elsevier: Oxford, UK, 2004.

86. Roggenbuck, O.; Reinking, J.; Härting, A. Oceanwide precise determination of sea surface height from in-situ measurements on cargo ships. Mar. Geod. 2014, 37, 77-96. [CrossRef]

87. Mostafavi, M.; Delpeche-Ellmann, N.; Ellmann, A. Accurate sea surface heights from Sentinel-3A and Jason-3 retrackers by incorporating high-resolution marine geoid and hydrodynamic models. J. Geod. Sci. 2021, 11, 58-74. [CrossRef]

88. Varbla, S.; Ellmann, A.; Delpeche-Ellmann, N. Utilizing airborne laser scanning and geoid model for near-coast improvements in sea surface height and marine dynamics. J. Coast. Res. 2020, 95, 1339-1343. [CrossRef]

89. Ardalan, A.A.; Jazireeyan, I.; Abdi, N.; Rezvani, M.-H. Evaluation of SARAL/AltiKa performance using GNSS/IMU equipped buoy in Sajafi, Imam Hassan and Kangan Ports. Adv. Space Res. 2018, 61, 1537-1545. [CrossRef]

90. Chupin, C.; Ballu, V.; Testut, L.; Tranchant, Y.-T.; Calzas, M.; Poirier, E.; Coulombier, T.; Laurain, O.; Bonnefond, P.; Team FOAM Project. Mapping sea surface height using new concepts of kinematic GNSS instruments. Remote Sens. 2020, 12, 2656. [CrossRef]

91. Zhou, B.; Watson, C.; Legresy, B.; King, M.A.; Beardsley, J.; Deane, A. GNSS/INS-equipped buoys for altimetry validation: Lessons learnt and new directions from the Bass Strait validation facility. Remote Sens. 2020, 12, 3001. [CrossRef] 